\title{
---Supporting Information---
}

\section{Manganese-Catalyzed Divergent Markovnikov Addition and [2+2+2] Cycloaddition of 2-Carbonyl Indanone with Terminal Alkyne}

Pradip Ramdas Thorve, Murali Mohan Guru, and Biplab Maji*

\author{
Department of Chemical Sciences \\ Indian Institute of Science Education and Research Kolkata \\ Mohanpur 741246 (India) \\ E-mail: bm@iiserkol.ac.in
}

Homepage: http://biplabmaji.wixsite.com/iiserkol

Table of Contents

\begin{tabular}{|l|l|l|}
\hline Sl. No. & Contents & Page No. \\
\hline 1. & Numbering of starting materials & S-2 \\
\hline 2. & KIE measurements & S-4 \\
\hline 3. & Crystallographic data & S-5 \\
\hline 4. & Copies of NMR spectra & S-7 \\
\hline
\end{tabular}


1. Numbering of starting materials:

1.1 Numbering of terminal acetylenes<smiles>C#Cc1ccccc1</smiles>

$2 a$<smiles>C#Cc1cc(F)cc(F)c1</smiles>

$2 \mathrm{e}$<smiles>C#CC</smiles>

$2 \mathrm{i}$<smiles>C#Cc1ccc(OC)cc1</smiles>

2b<smiles>C#Cc1cc(OC)c(OC)c(OC)c1</smiles>

$2 f$<smiles>C#Cc1cccc(C)c1</smiles>

2j<smiles>C#Cc1ccc(-c2ccccc2)cc1</smiles>

2c

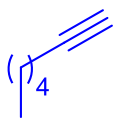

$2 g$<smiles>C#Cc1ccc(C)cc1</smiles>

2d

\subsection{Numbering of 1,3-diketone compounds}<smiles>CC(=O)C1Cc2ccccc2C1=O</smiles>

$1 \mathrm{a}$<smiles>CC(=O)C1Cc2cc(F)ccc2C1=O</smiles>

$1 d$<smiles>O=C1c2ccccc2CC1C(=O)C1CC1</smiles>

$1 \mathrm{~g}$<smiles>COc1ccc2c(c1)CC(C(C)=O)C2=O</smiles>

1b<smiles>O=C(CCc1ccccc1)C1Cc2ccccc2C1=O</smiles>

$1 \mathrm{e}$<smiles>CC(=O)C1Cc2cc(-c3ccccc3)ccc2C1=O</smiles>

1c<smiles>CCOC(=O)C1Cc2ccccc2C1=O</smiles>

$1 f$ 
1.3 Numbering of $\beta$-ketoester compounds<smiles>CCOC(=O)C1Cc2ccccc2C1=O</smiles>

$4 a$<smiles>CCOC(=O)C1Cc2cc(-c3ccccc3)ccc2C1=O</smiles>

4d<smiles>CCOC(=O)C1Cc2cc(OC)c(OC)cc2C1=O</smiles>

$4 g$<smiles>COC(=O)C1Cc2ccccc2C1=O</smiles>

4b

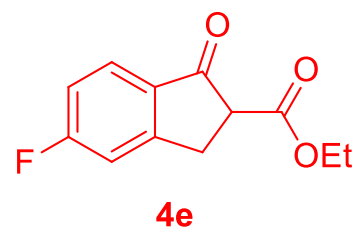<smiles>CCOC(=O)C1Cc2cc(OC)ccc2C1=O</smiles>

4c<smiles>CCOC(=O)C1Cc2cc(Br)ccc2C1=O</smiles> 


\section{KIE measurements:}

Parallel experiments for KIE with deuterated $\beta$-ketoester.
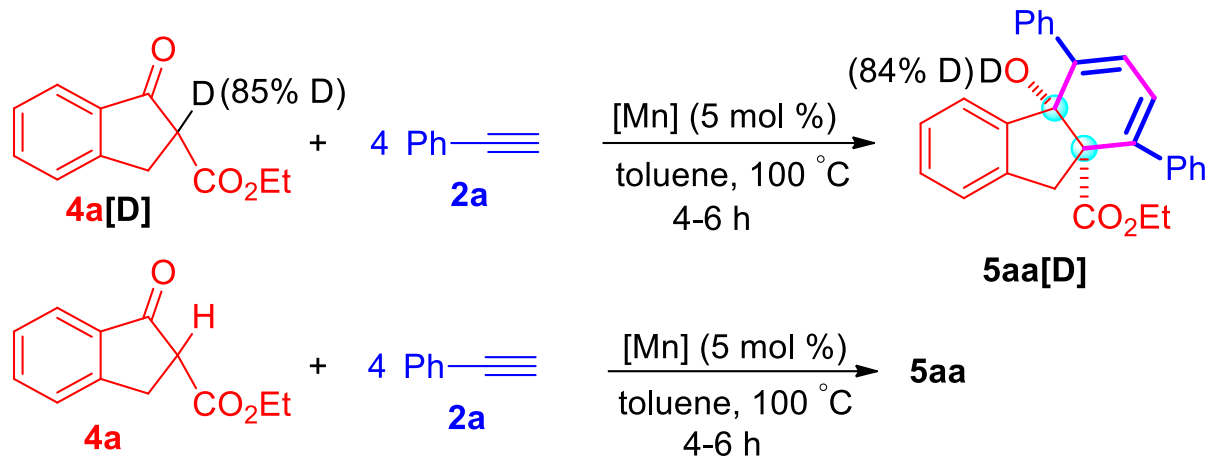

5aa[D]

\begin{tabular}{|c|c|c|c|}
\hline time $(\mathrm{h})$ & yield of 5aa[D] $(\%)$ & yield of 5aa $(\%)$ & $k_{\mathrm{H}} / k_{\mathrm{D}}$ \\
\hline 4 & 10 & 12 & 1.20 \\
\hline 5 & 16 & 20 & 1.25 \\
\hline 6 & 29 & 24 & 1.20 \\
\hline 10 & 53 & 44 & 1.20 \\
\hline
\end{tabular}

Average $k_{\mathrm{H}} / k_{\mathrm{D}}=1.21$

Parallel experiments for KIE with deuterated phenylacetylene.

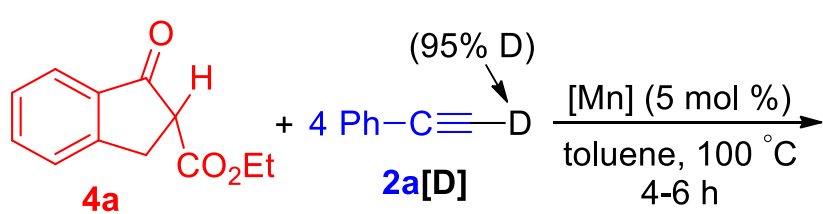<smiles>CCOC1Cc2ccccc2C1=O</smiles>

$4 a$
4-6 $\mathrm{h}$

$$
+4 \mathrm{Ph} \underset{2 \mathrm{a}}{\stackrel{ }{\equiv}} \mathrm{H} \frac{[\mathrm{Mn}](5 \mathrm{~mol} \%)}{\begin{array}{c}
\text { toluene, } 100{ }^{\circ} \mathrm{C} \\
4-6 \mathrm{~h}
\end{array}}
$$

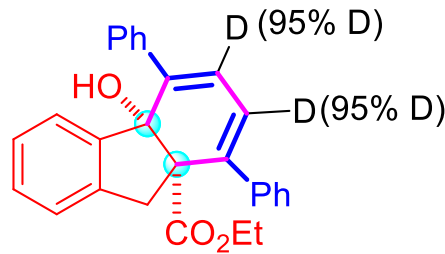

5aa[D2]

\begin{tabular}{|c|c|c|c|}
\hline time $(\mathrm{h})$ & yield of 5aa[D2] $(\%)$ & yield of 5aa $(\%)$ & $k_{\mathrm{H}} / k_{\mathrm{D}}$ \\
\hline 4 & 9 & 12 & 1.33 \\
\hline 5 & 15 & 20 & 1.33 \\
\hline 6 & 22 & 29 & 1.32 \\
\hline
\end{tabular}

$k_{\mathrm{H}} / k_{\mathrm{D}}=1.33$ 


\section{Crystallographic structure and data of 5aa.}

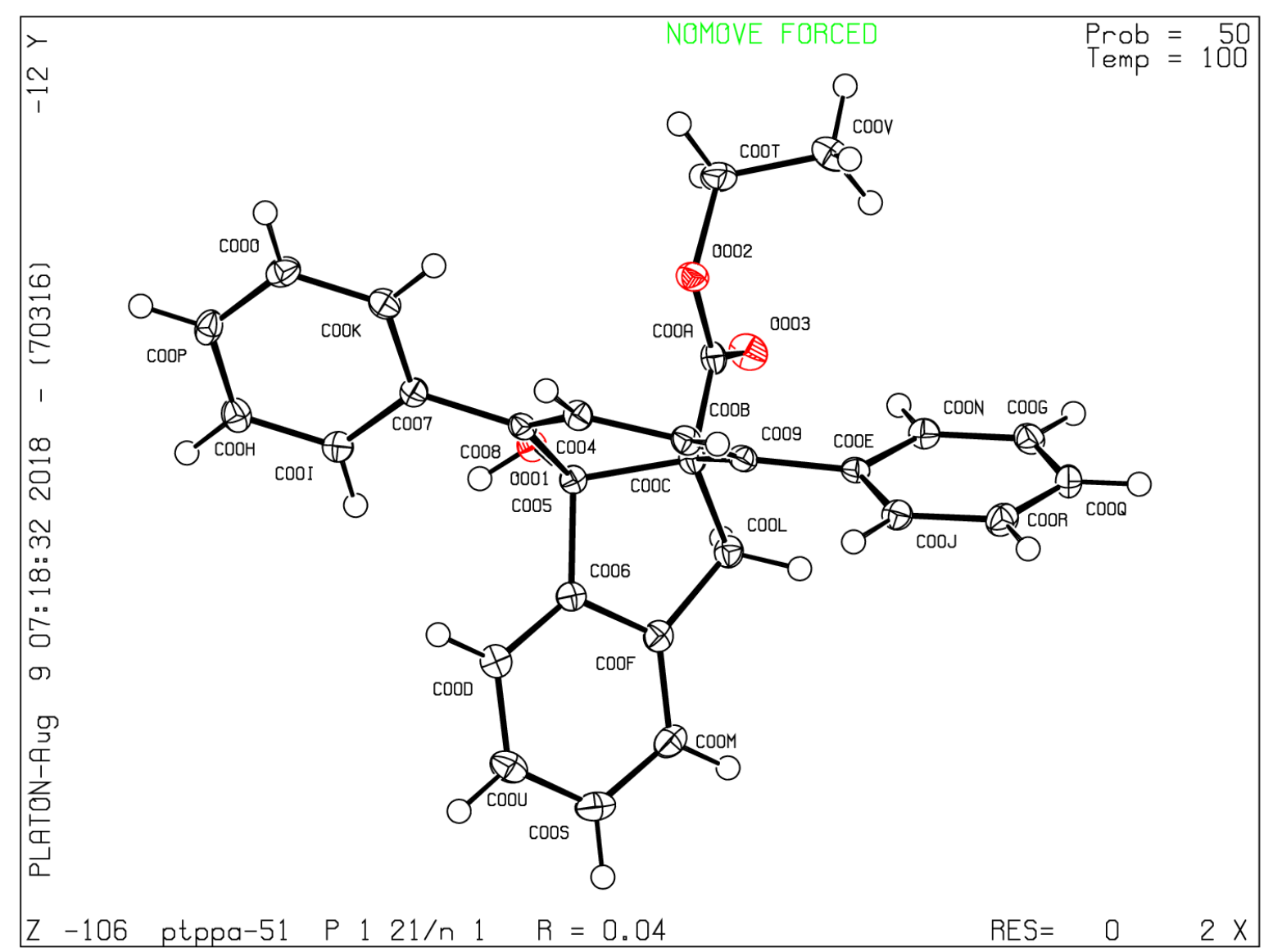

Colorless crystals of 5aa for single crystal X-ray analysis were obtained by slow evaporation of hexane/ethylacetate (49:1) solution of 5aa at room temperature. M.P. $=155^{\circ} \mathrm{C}$. 
Table S1. Crystal data and structure refinement for $5 \mathrm{ba}$.

Identification code PTPPA-51

Empirical formula

$\mathrm{C}_{28} \mathrm{H}_{24} \mathrm{O}_{3}$

Formula weight

408.47

Temperature/K

100.00(10)

Crystal system

monoclinic

Space group

$\mathrm{P} 2{ }_{1} / \mathrm{n}$

$\mathrm{a} / \AA$

8.4827(2)

$\mathrm{b} / \AA$

11.6842(3)

c/Å

20.2986(5)

$\alpha /{ }^{\circ}$

90

$\beta /{ }^{\circ}$

93.727(2)

$\gamma /{ }^{\circ}$

90

Volume $/ \AA^{3}$

2007.61(9)

Z

4

$\rho_{\text {calc }} \mathrm{g} / \mathrm{cm}^{3}$

1.351

$\mu / \mathrm{mm}^{-1}$

0.087

$\mathrm{F}(000)$

864.0

Crystal size $/ \mathrm{mm}^{3}$

$0.29 \times 0.26 \times 0.21$

Radiation

$\operatorname{MoK} \alpha(\lambda=0.71073)$

$2 \theta$ range for data collection ${ }^{\circ}$

4.022 to 55.392

Index ranges

$-11 \leq \mathrm{h} \leq 10,-14 \leq \mathrm{k} \leq 14,-25 \leq 1 \leq 26$

Reflections collected

16665

Independent reflections

$4287\left[R_{\text {int }}=0.0305, R_{\text {sigma }}=0.0283\right]$

Data/restraints/parameters

$4287 / 0 / 282$

Goodness-of-fit on $\mathrm{F}^{2}$

1.069

Final $\mathrm{R}$ indexes $[\mathrm{I}>=2 \sigma(\mathrm{I})]$

$\mathrm{R}_{1}=0.0444, \mathrm{wR}_{2}=0.1033$

Final $\mathrm{R}$ indexes [all data]

$\mathrm{R}_{1}=0.0520, \mathrm{wR}_{2}=0.1074$

Largest diff. peak/hole / e $\AA^{-3}$

$0.33 /-0.27$ 


\section{Copies of NMR spectra}

\section{${ }^{1} \mathrm{H}$ NMR (400 MHz, CDCl 3$)$ :}

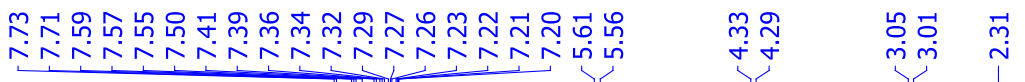
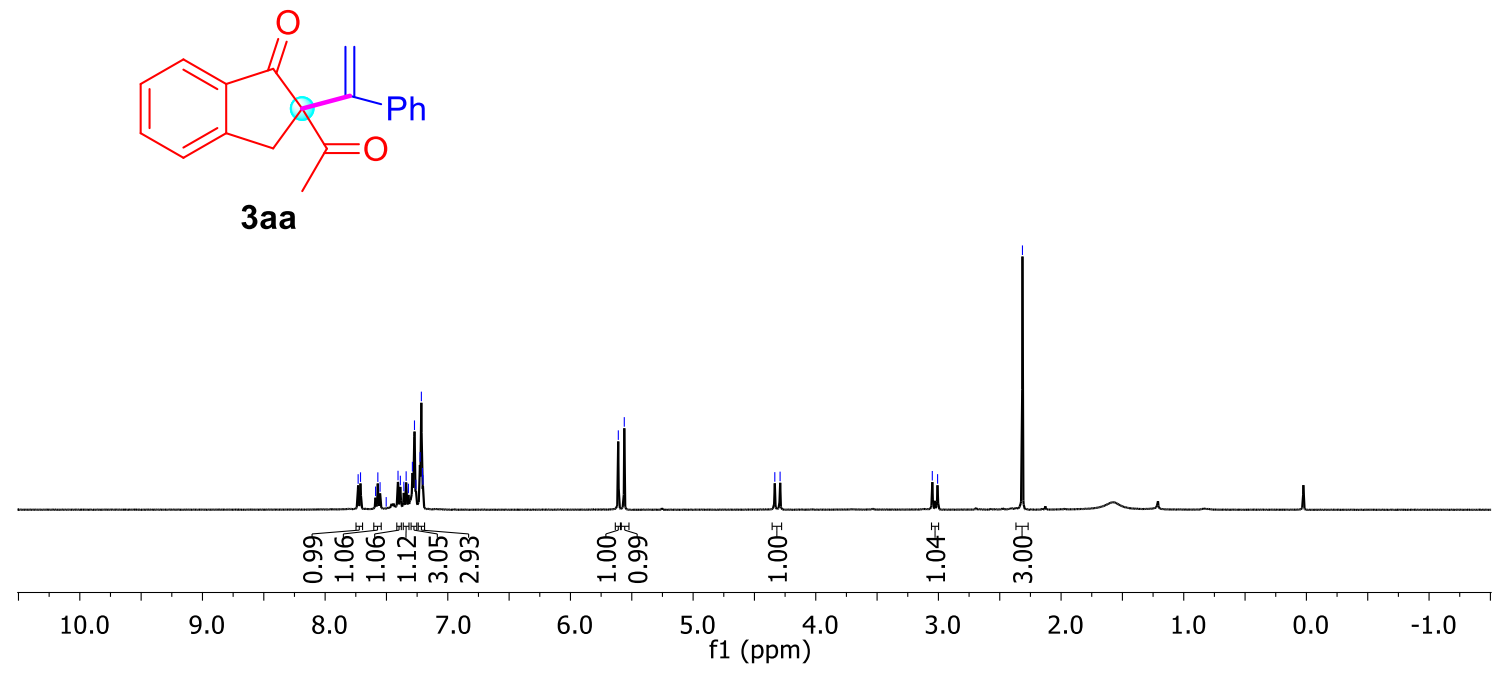

${ }^{13}$ C NMR (126 MHz, CDCl3):
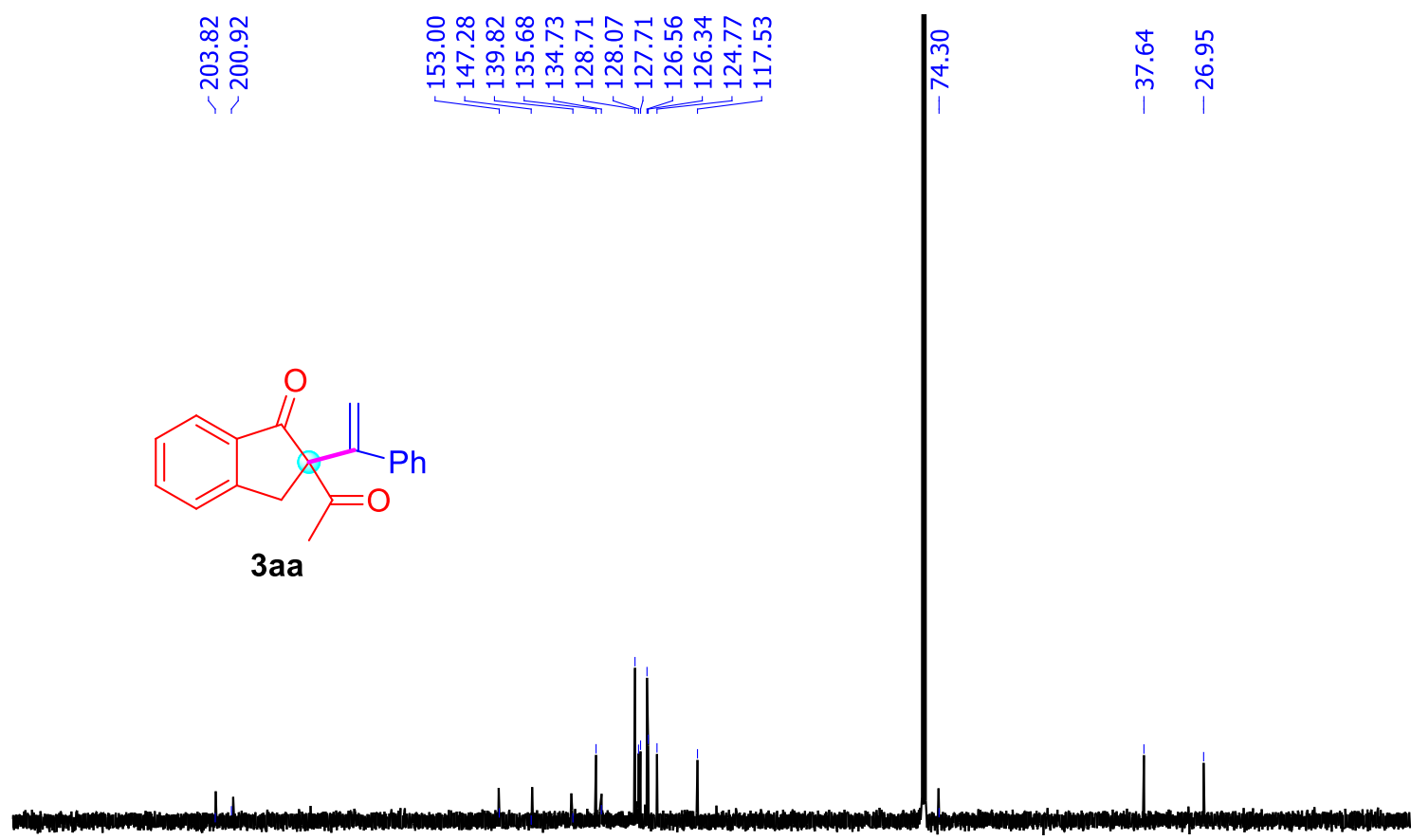

230

190

170

150

$130 \begin{array}{r}110 \\ \mathrm{f} 1(\mathrm{ppm})\end{array}$

$\begin{array}{llllllllll}90 & 80 & 70 & 60 & 50 & 40 & 30 & 20 & 10 & 0\end{array}$ 
${ }^{1} \mathrm{H}$ NMR (400 MHz, $\left.\mathrm{CDCl}_{3}\right)$ :

ஜํำ

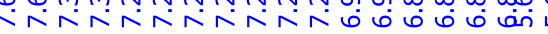

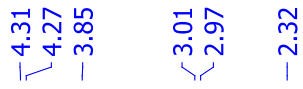<smiles>C=C(c1ccccc1)C1(C(C)=O)Cc2ccc(OC)cc2C1=O</smiles>

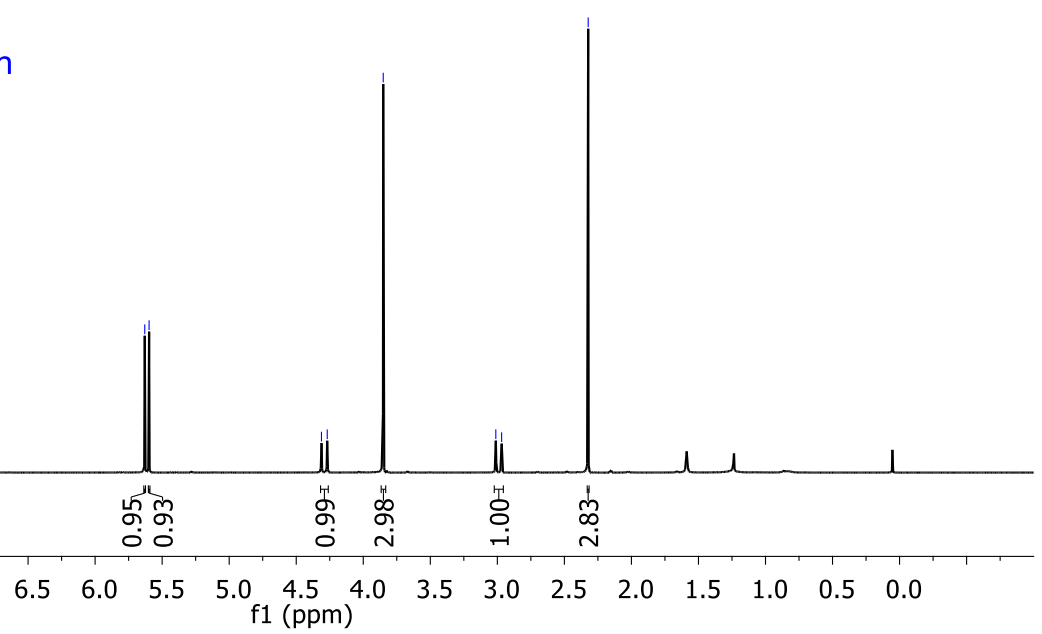

${ }^{13} \mathrm{C}$ NMR (126 MHz, $\left.\mathrm{CDCl}_{3}\right)$ :

影暴

ㄲํํำ

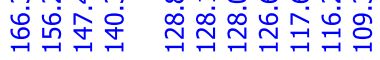

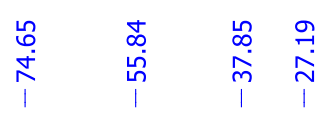

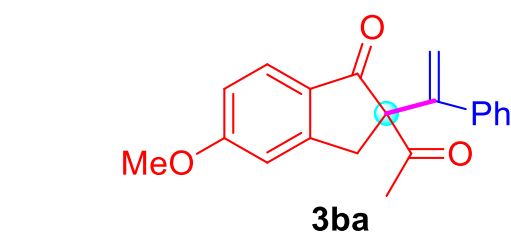

230

210

190

170

150

130 f1 (ppm)

$\begin{array}{llllllllll}90 & 80 & 70 & 60 & 50 & 40 & 30 & 20 & 10 & 0\end{array}$ 
${ }^{1} \mathrm{H}$ NMR (400 MHz, $\left.\mathrm{CDCl}_{3}\right)$ :

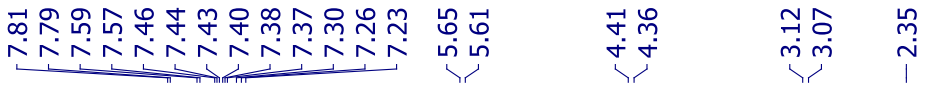<smiles>C=C(c1ccccc1)C1(C(=O)[Ge])Cc2cc(-c3ccccc3)ccc2C1=O</smiles>

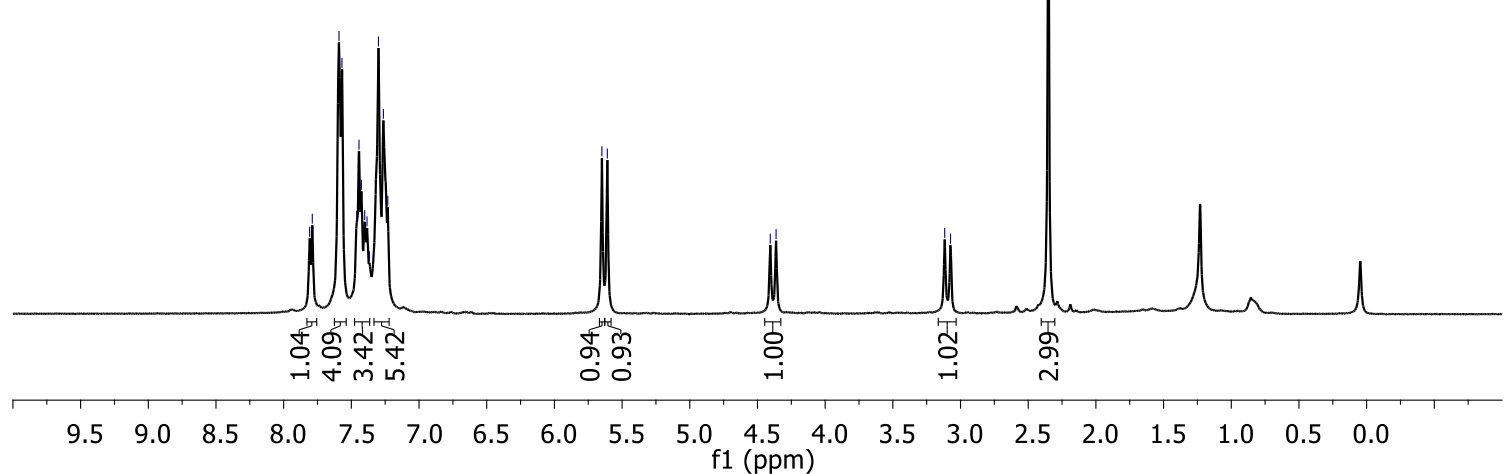

${ }^{13} \mathrm{C}$ NMR (126 MHz, CDCl 3$)$ :

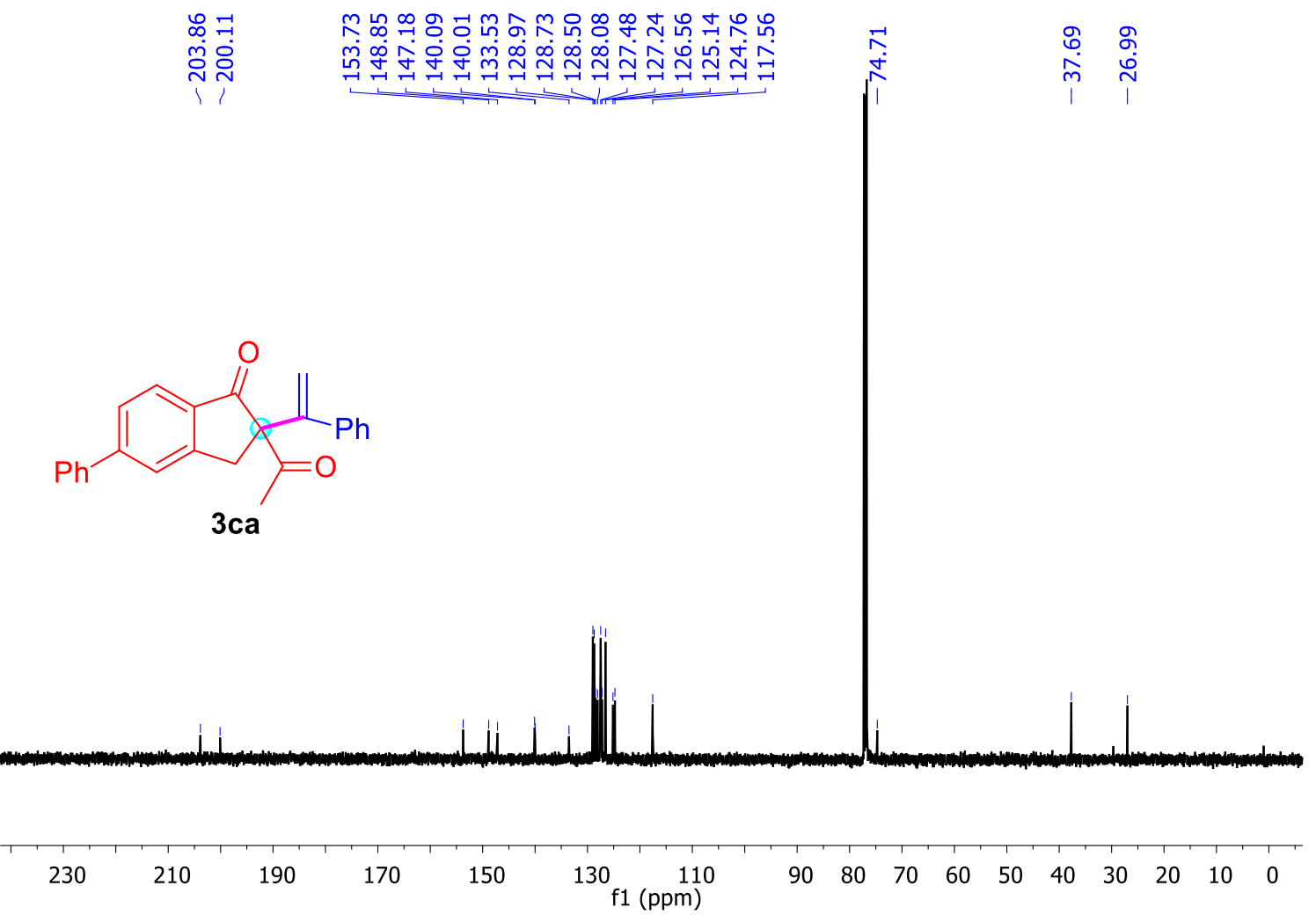


${ }^{1} \mathrm{H}$ NMR (400 MHz, $\left.\mathrm{CDCl}_{3}\right)$ :

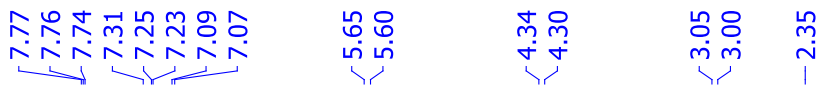<smiles>C=C(c1ccccc1)C1(C(C)=O)Cc2cc(F)ccc2C1=O</smiles>

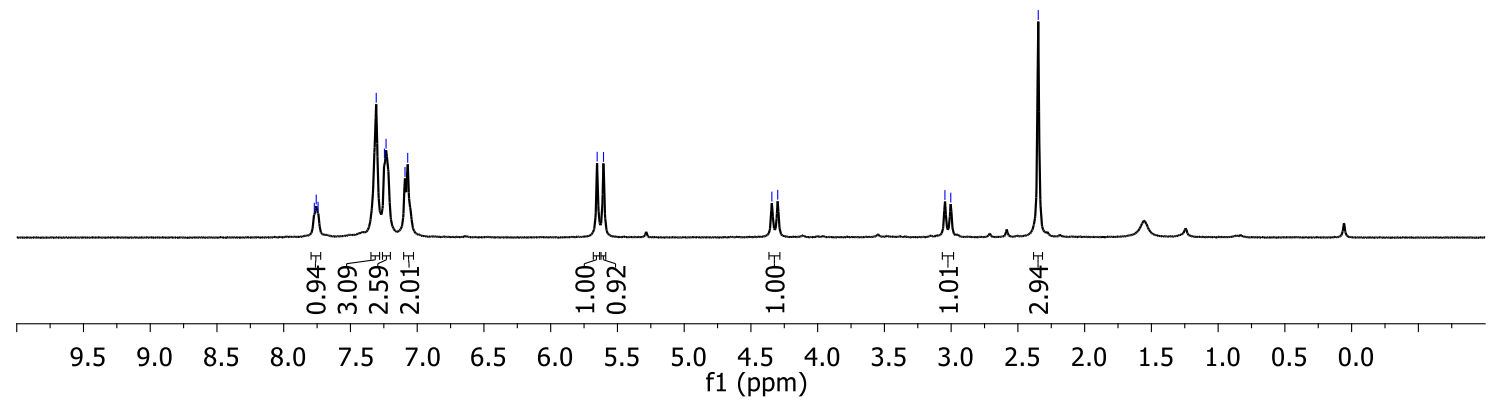

${ }^{13} \mathrm{C}$ NMR (126 MHz, CDCl3):

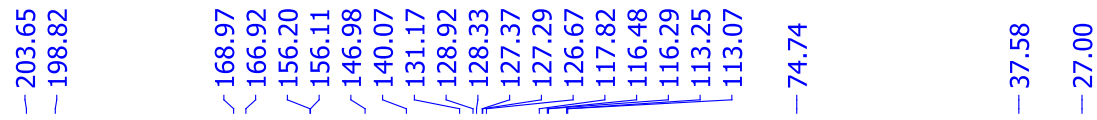<smiles>C=C(c1ccccc1)C1(C(C)=O)Cc2cc(F)ccc2C1=O</smiles>

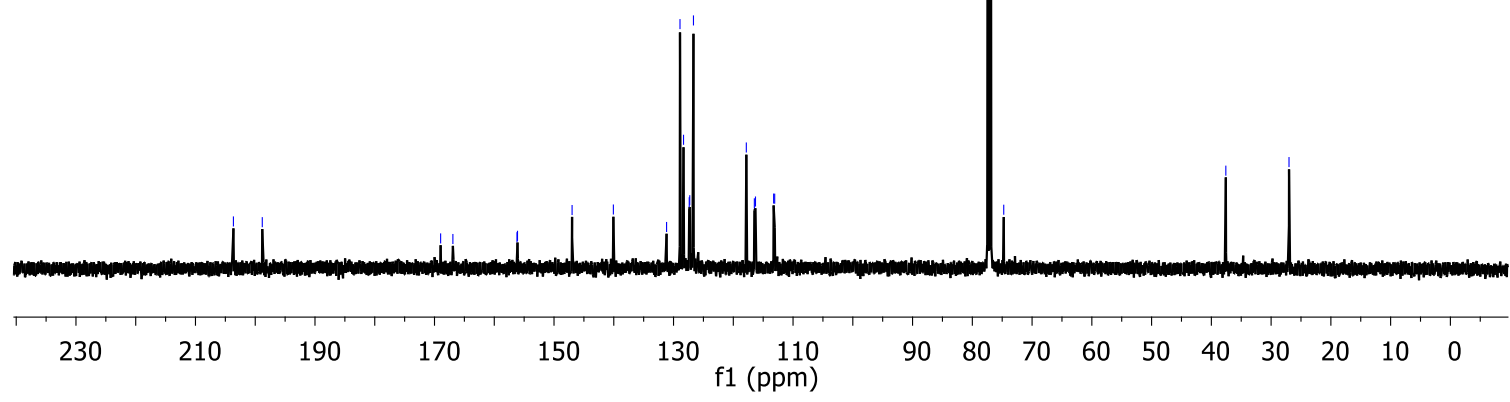


${ }^{19}$ F NMR (471 MHz, CDCl3):

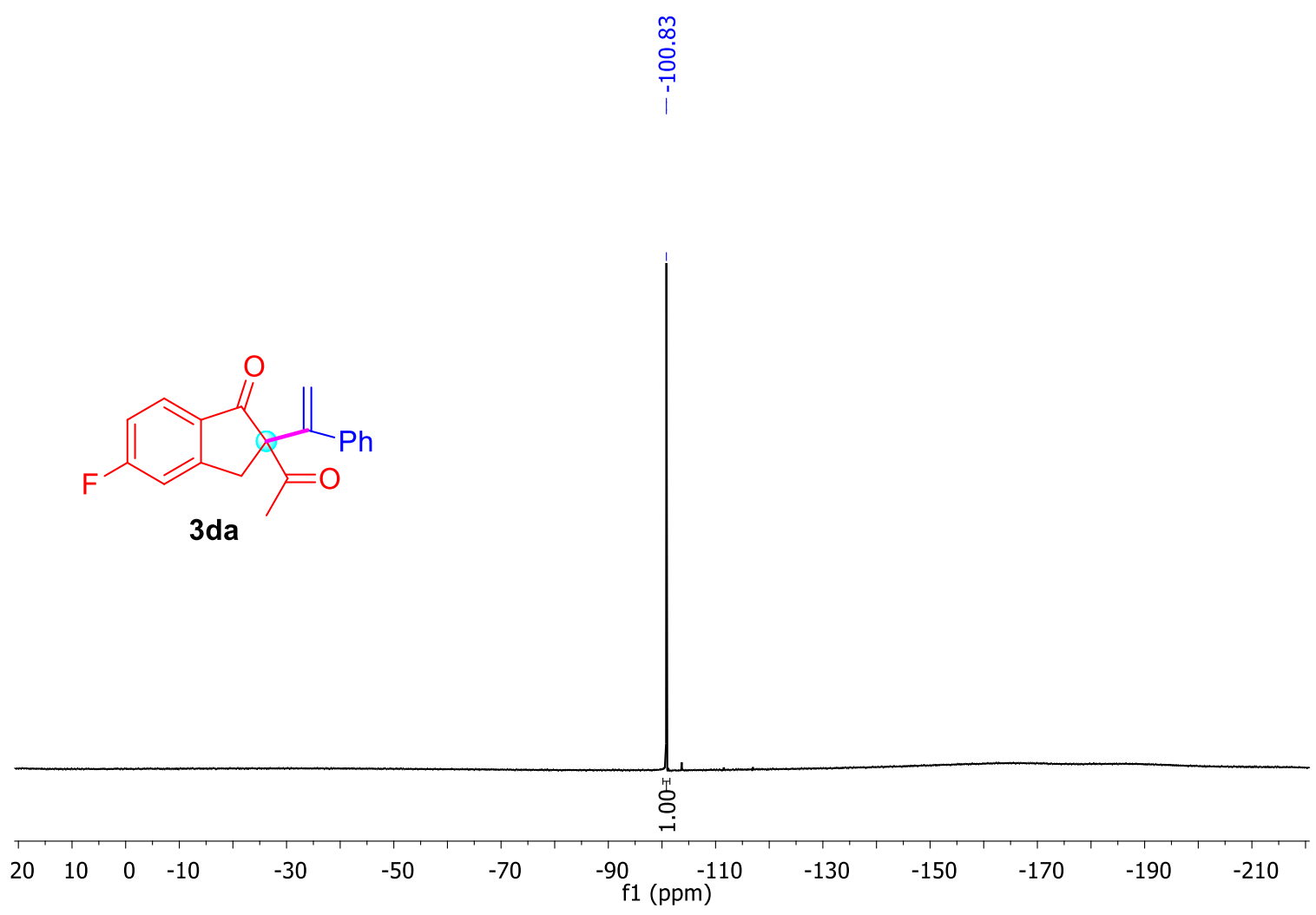

${ }^{1} \mathrm{H}$ NMR (400 MHz, CDCl3):

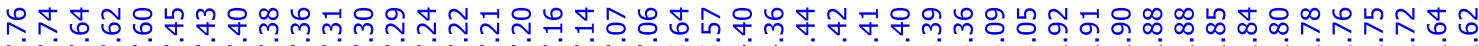

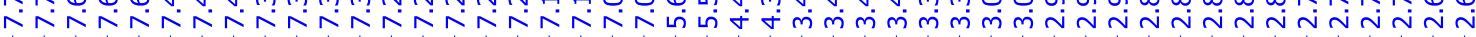

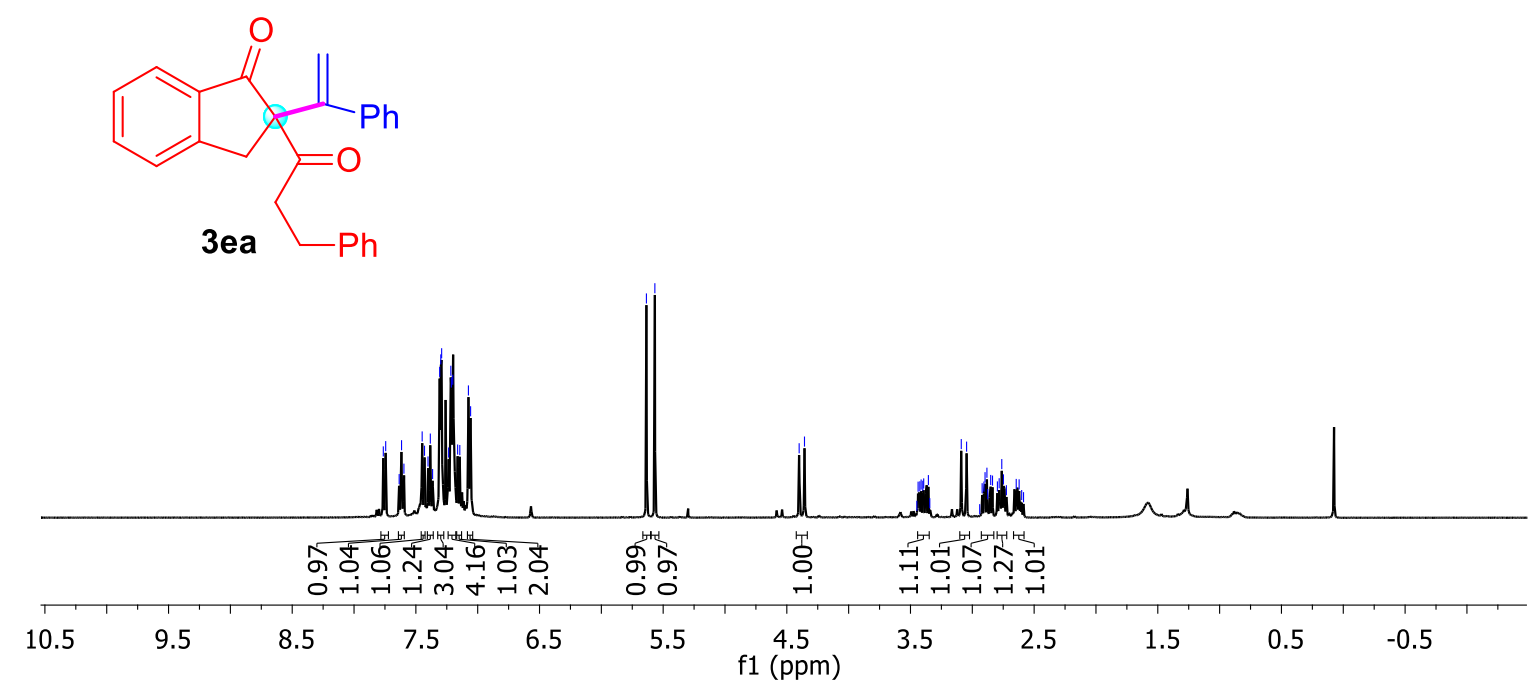


${ }^{13} \mathrm{C}$ NMR (126 MHz, CDCl3):

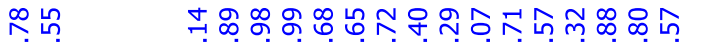

实官

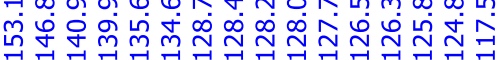

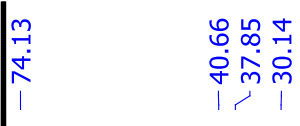
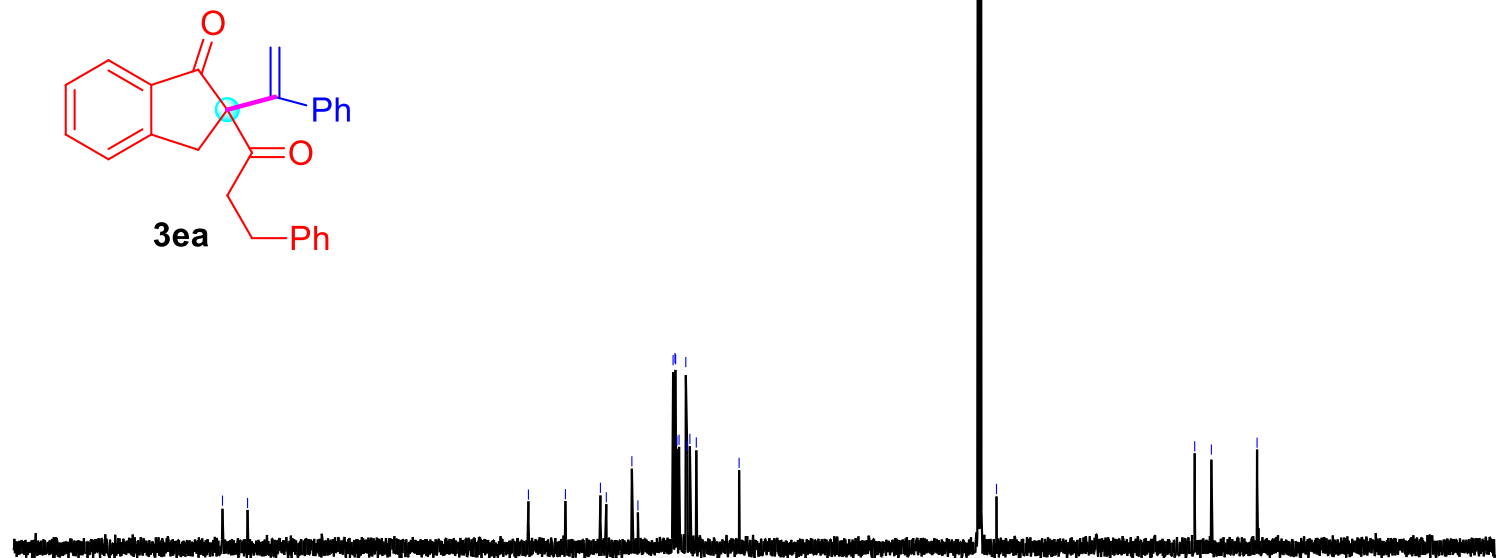

230

210

190

$170 \quad 150$

130

$\begin{array}{llllllllll}90 & 80 & 70 & 60 & 50 & 40 & 30 & 20 & 10 & 0\end{array}$

${ }^{1} \mathrm{H}$ NMR (400 MHz, $\left.\mathrm{CDCl}_{3}\right)$ :

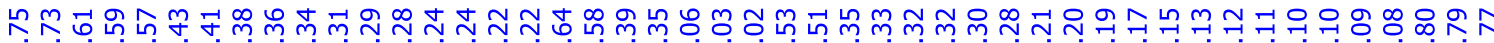

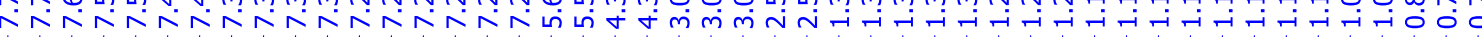<smiles>C=C(C(=O)N(C)c1ccccc1)C1(C(=O)OC)Cc2ccccc2C1=O</smiles>

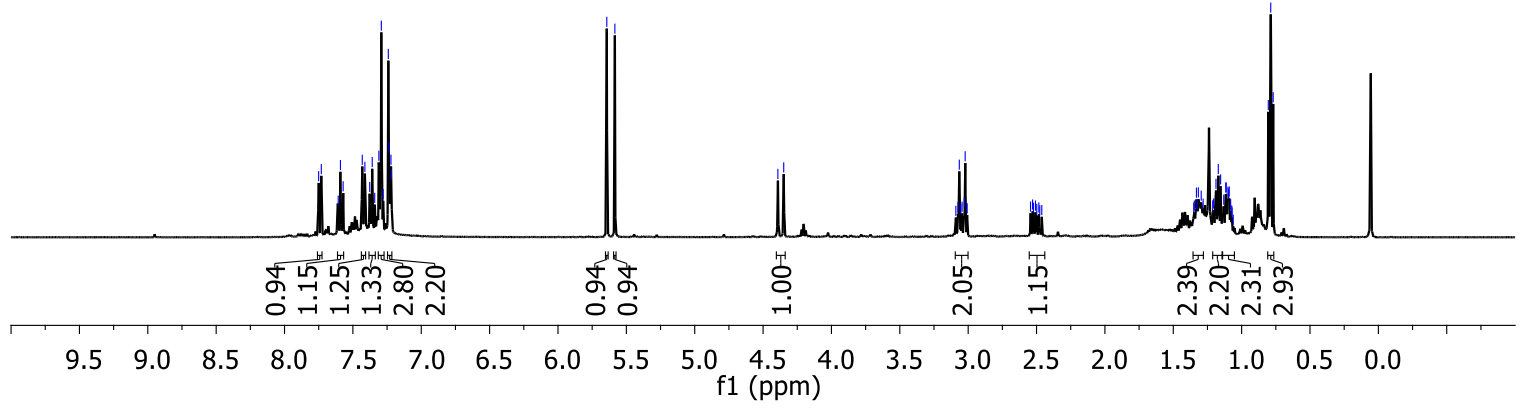


${ }^{13}$ C NMR (126 MHz, CDCl3):

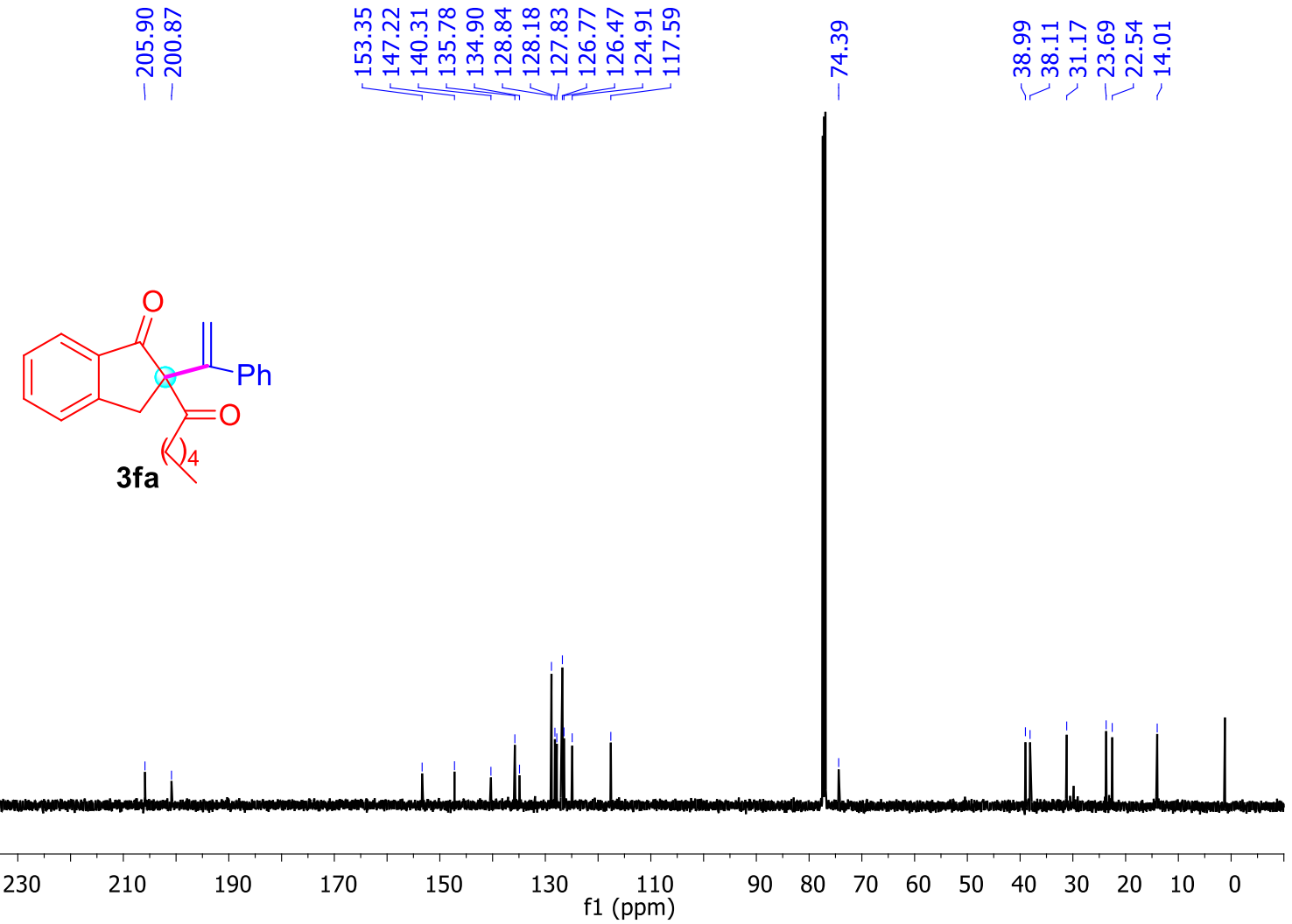

${ }^{1} \mathrm{H}$ NMR (500 MHz, $\left.\mathrm{CDCl}_{3}\right)$ :

\begin{tabular}{|c|c|c|}
\hline 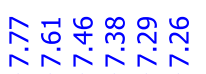 & 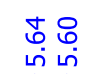 & 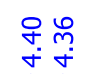 \\
\hline
\end{tabular}

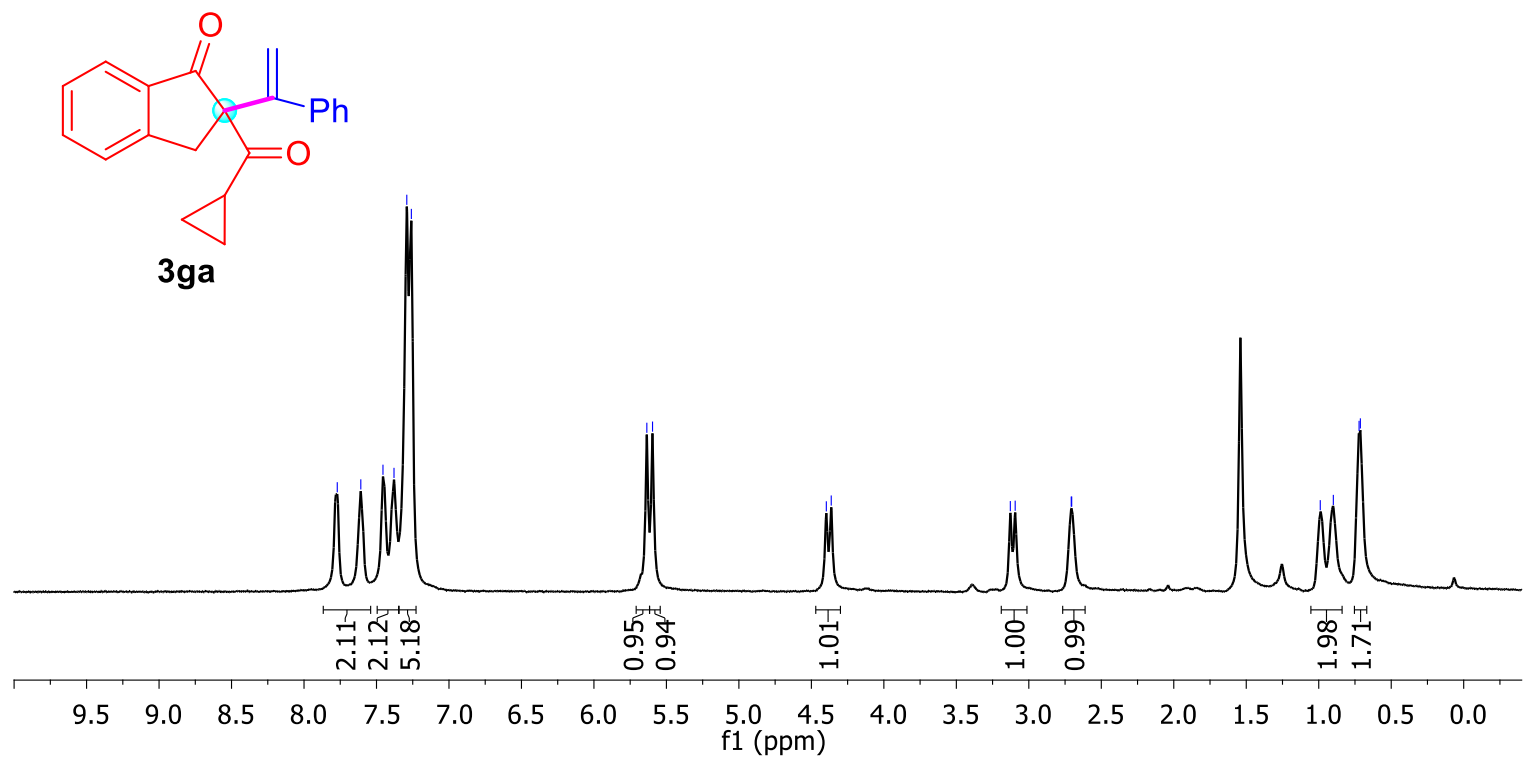


${ }^{13}$ C NMR (126 MHz, CDCl3):

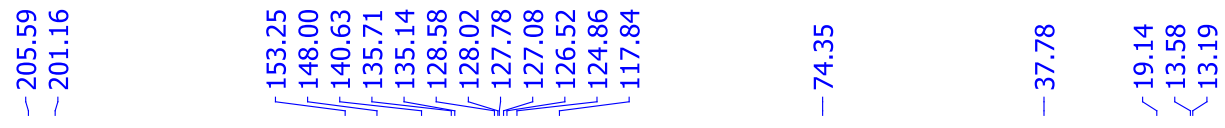

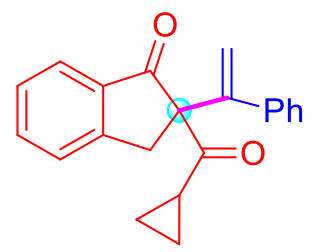

3ga

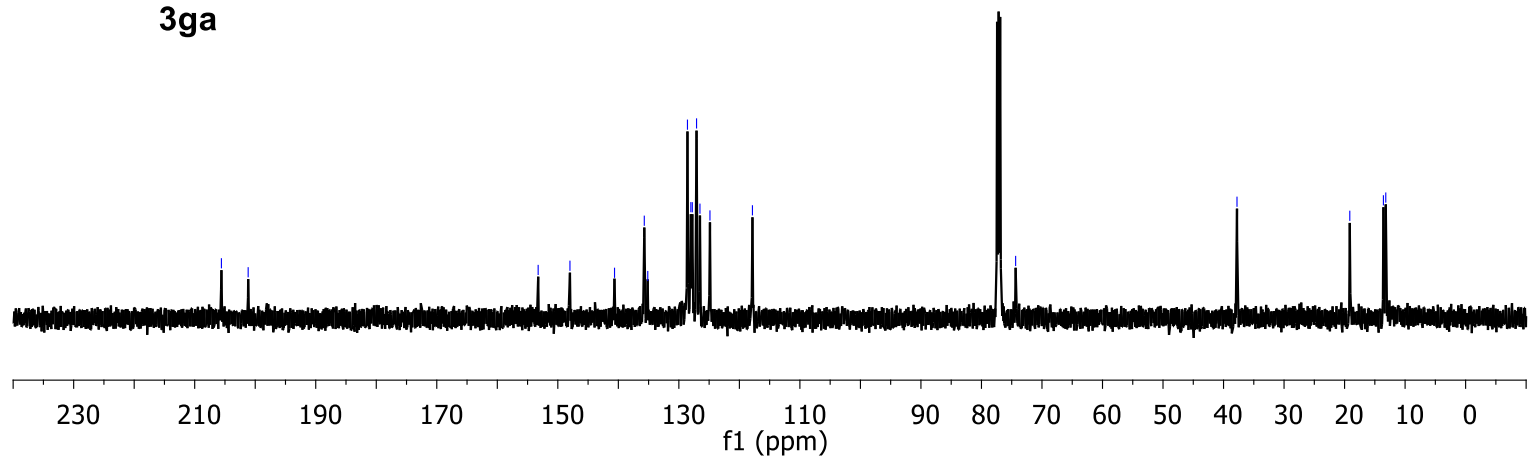

${ }^{1} \mathrm{H}$ NMR (400 MHz, $\left.\mathrm{CDCl}_{3}\right)$ :

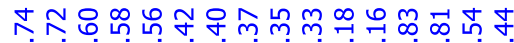

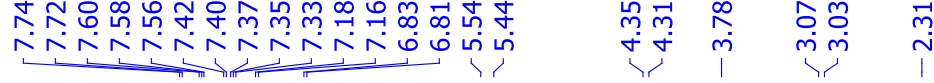<smiles>C=C(c1ccc(OC)cc1)C1(C(C)=O)Cc2ccccc2C1=O</smiles>

$3 a b$ 


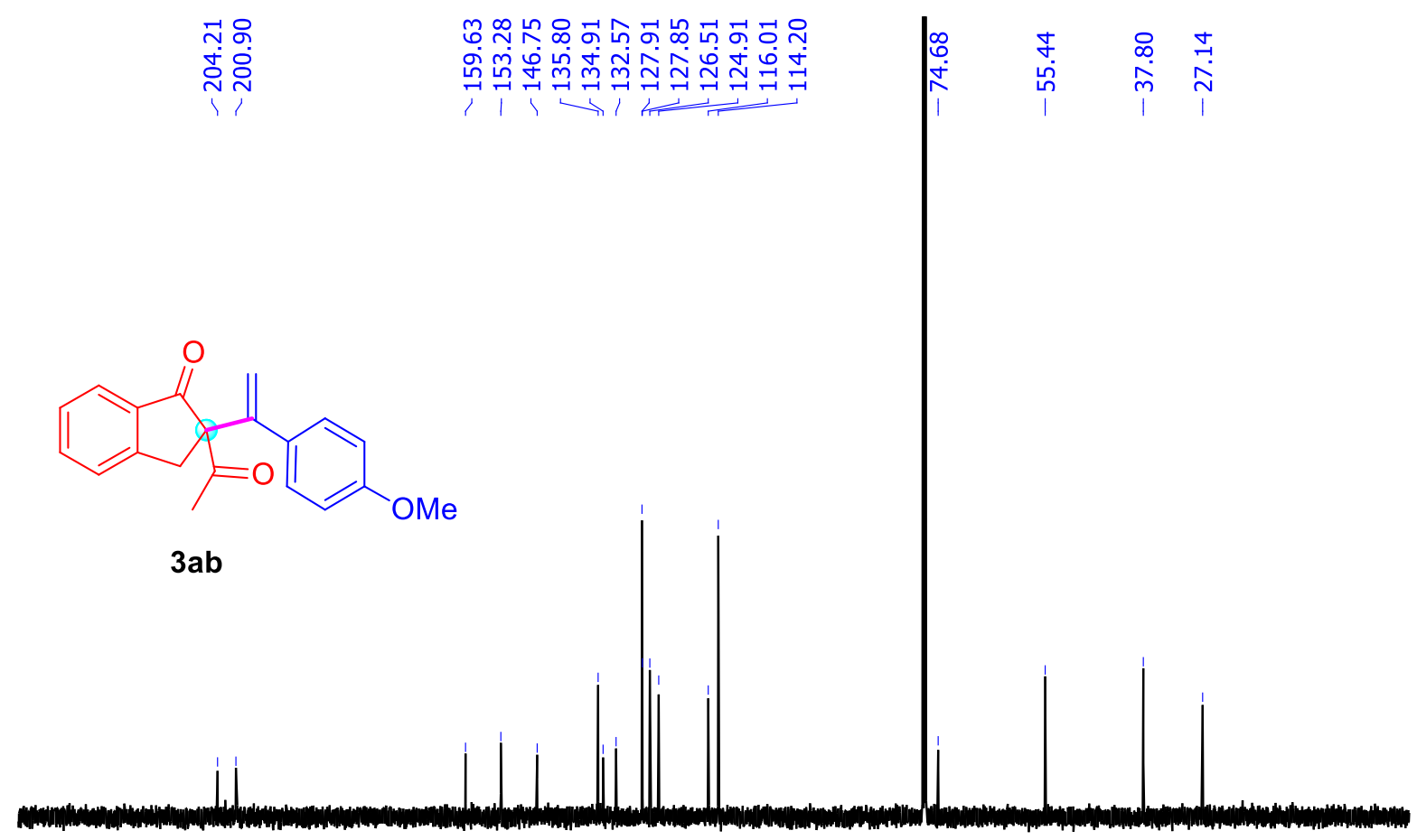

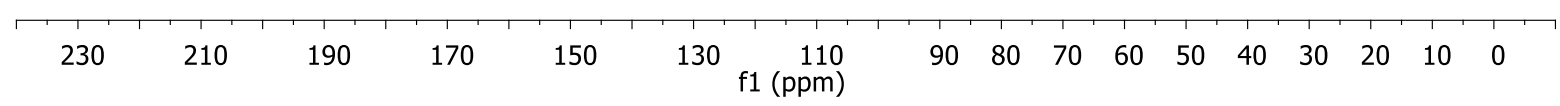

${ }^{1}$ H NMR (400 MHz, CDCl3):

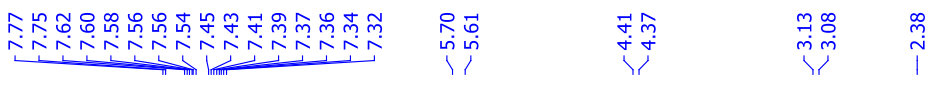<smiles></smiles>

$3 a c$

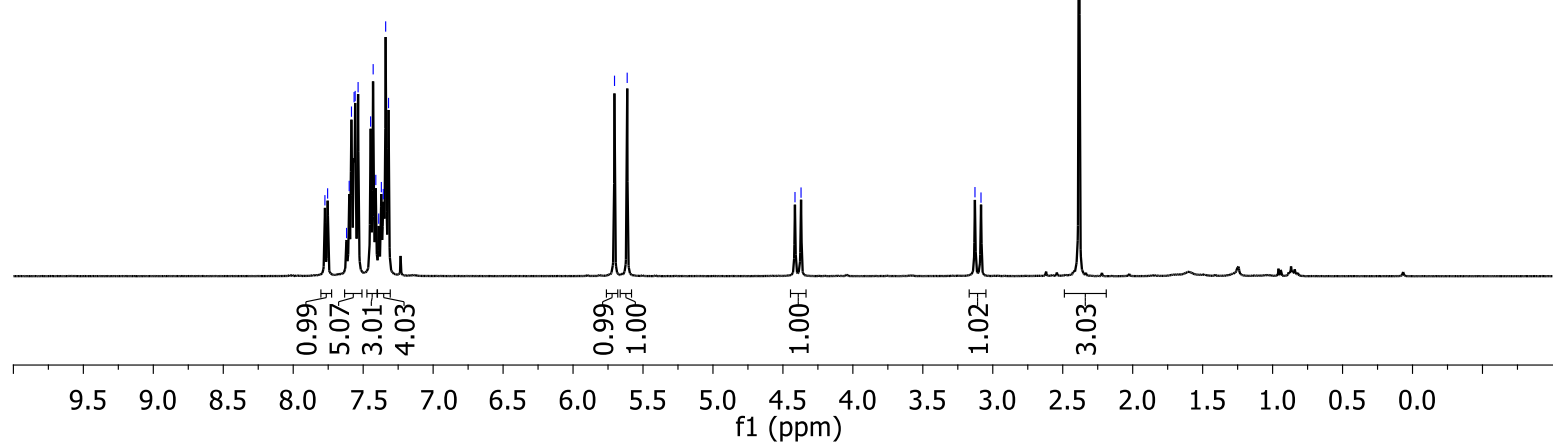


${ }^{13} \mathrm{C}$ NMR (126 $\left.\mathrm{MHz}, \mathrm{CDCl}_{3}\right)$ :

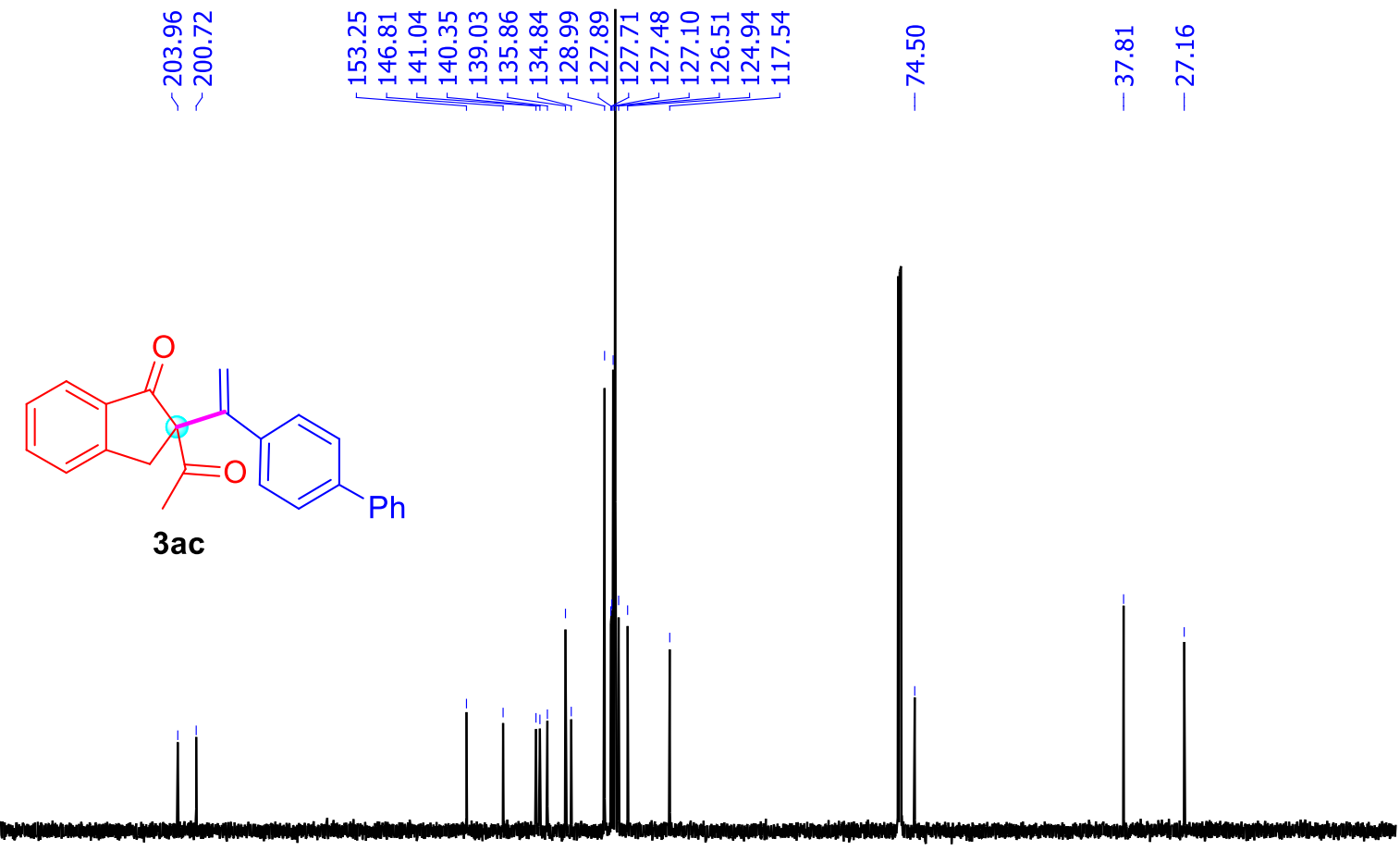

\begin{tabular}{llllllllllllllllll}
\hline 230 & 210 & 190 & 170 & 150 & $130 \begin{array}{r}110 \\
\mathrm{f} 1(\mathrm{ppm})\end{array}$ & 90 & 80 & 70 & 60 & 50 & 40 & 30 & 20 & 10 & 0
\end{tabular}

${ }^{1} \mathrm{H}$ NMR (400 MHz, CDCl3):

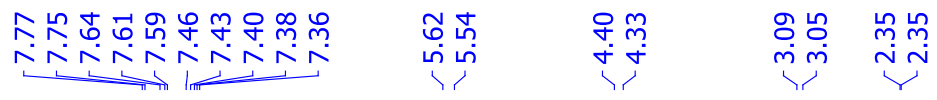
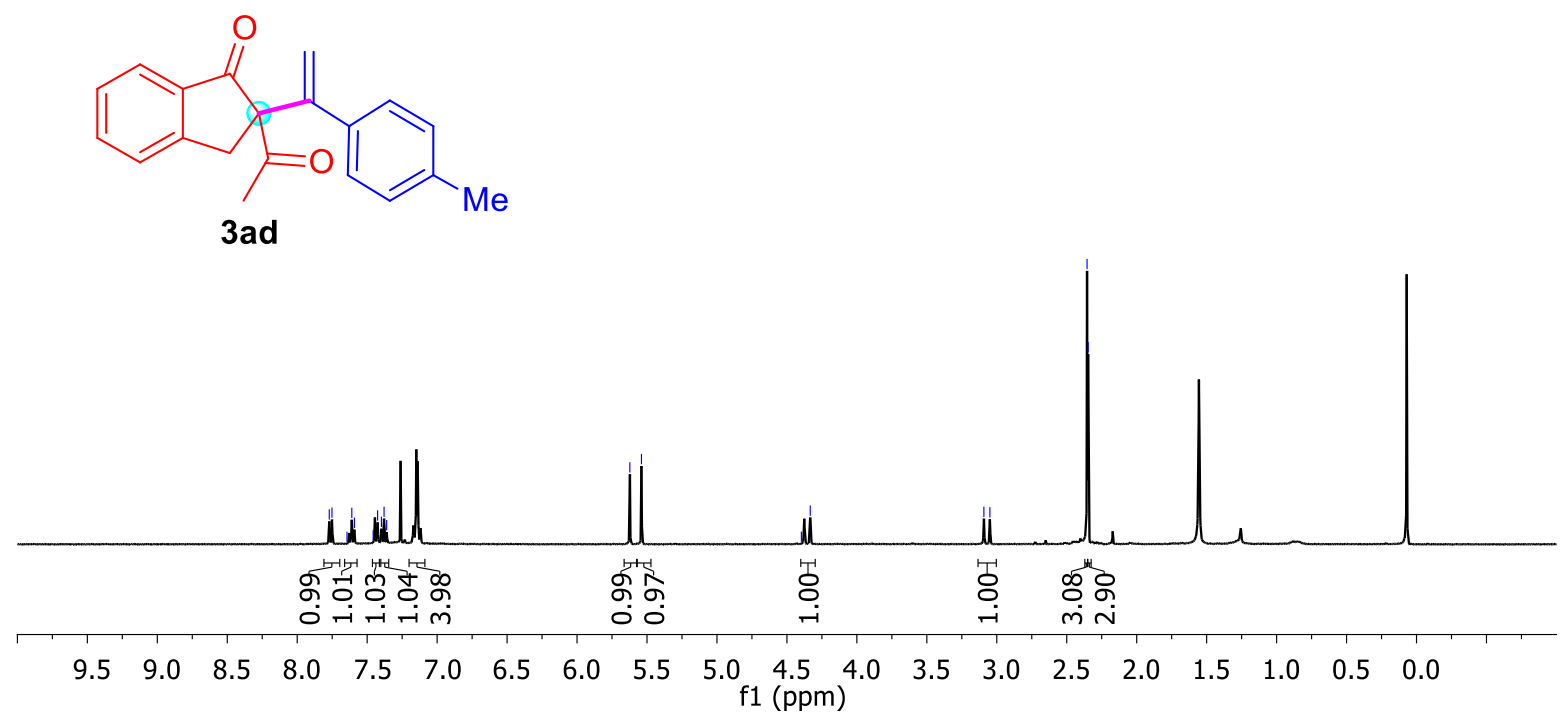
${ }^{13}$ C NMR (126 MHz, CDCl3):

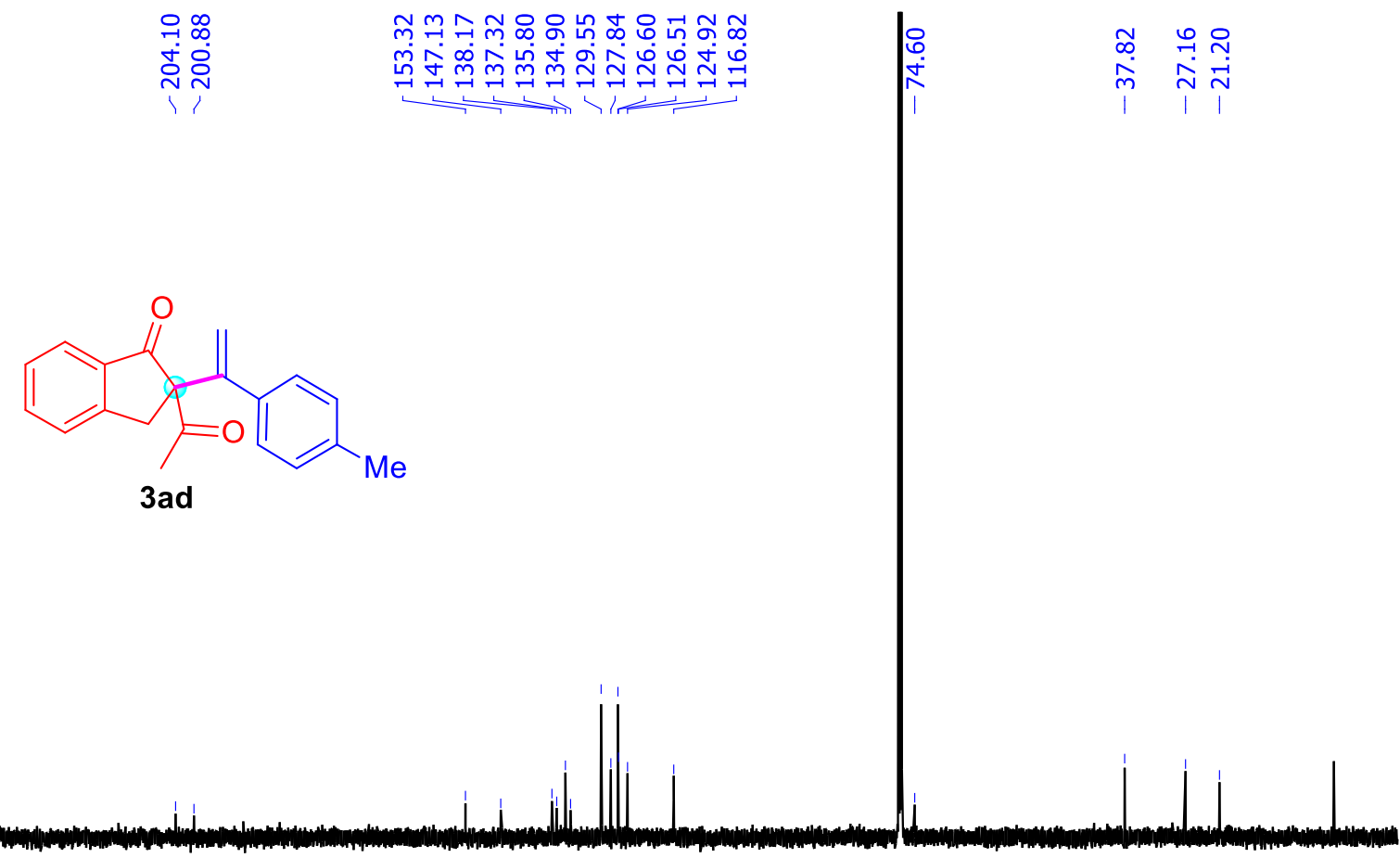

\begin{tabular}{llllllllllllllllll}
\hline 230 & 210 & 190 & 170 & 150 & $130 \begin{array}{r}110 \\
\mathrm{f} 1(\mathrm{ppm})\end{array}$ & 90 & 80 & 70 & 60 & 50 & 40 & 30 & 20 & 10 & 0
\end{tabular}

${ }^{1} \mathrm{H}$ NMR (500 MHz, CDCl3):

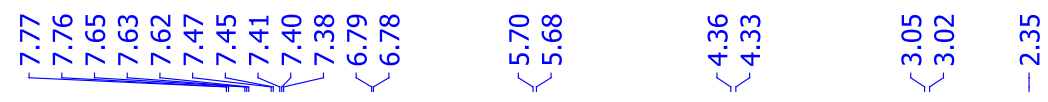<smiles>C=C(C(C)=O)C1C(=O)C2C(=O)c3ccccc3C12</smiles>

$3 a e$

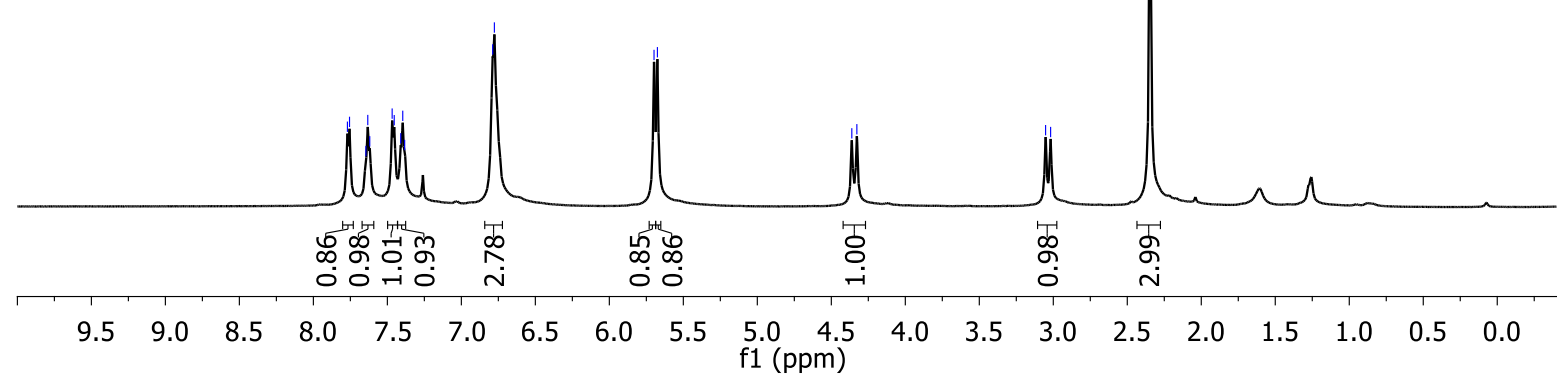


${ }^{13}$ C NMR (126 MHz, CDCl3):

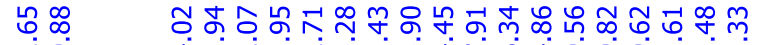

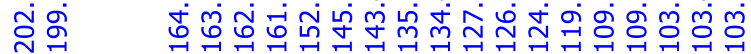<smiles>C=C(c1cc(F)cc(F)c1)C1(C(C)=O)Cc2ccccc2C1=O</smiles>

$\begin{array}{llllllllllllllll}230 & 210 & 190 & 170 & 150 & 130 \begin{array}{r}110 \\ \mathrm{f} 1(\mathrm{ppm})\end{array} & 90 & 80 & 70 & 60 & 50 & 40 & 30 & 20 & 10 & 0\end{array}$

${ }^{19}$ F NMR (471 MHz, CDCl3):

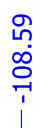<smiles>C=C(C(C)=O)C1C(=O)C2C(=O)c3ccccc3C12</smiles> 
${ }^{1} \mathrm{H}$ NMR (400 MHz, CDCl3):

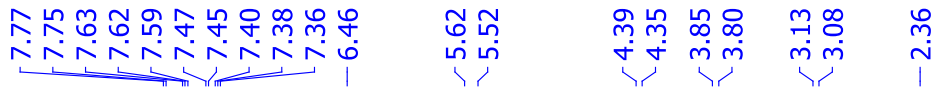
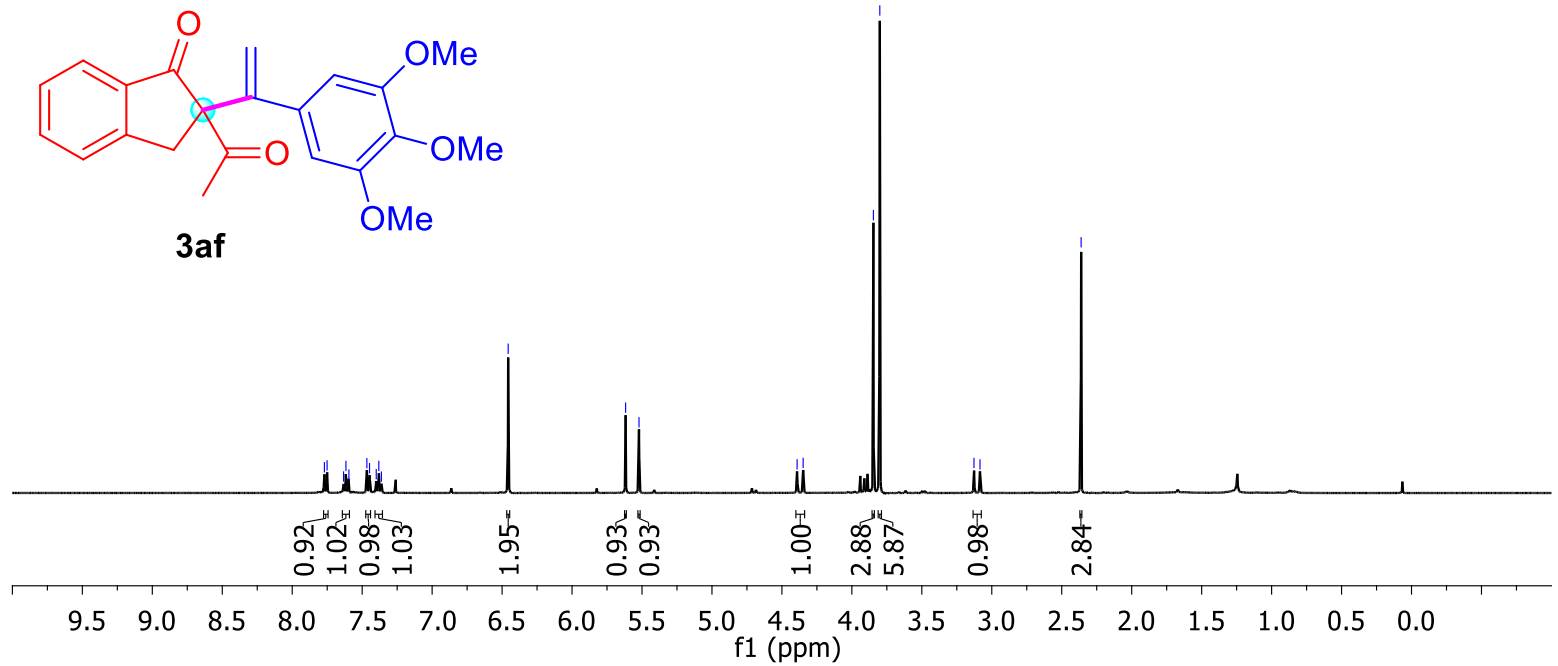

${ }^{13} \mathrm{C}$ NMR (126 MHz, CDCl3):

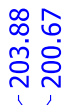

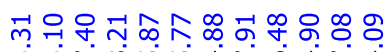

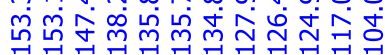

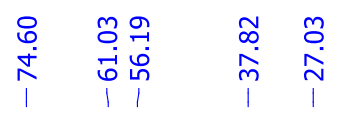
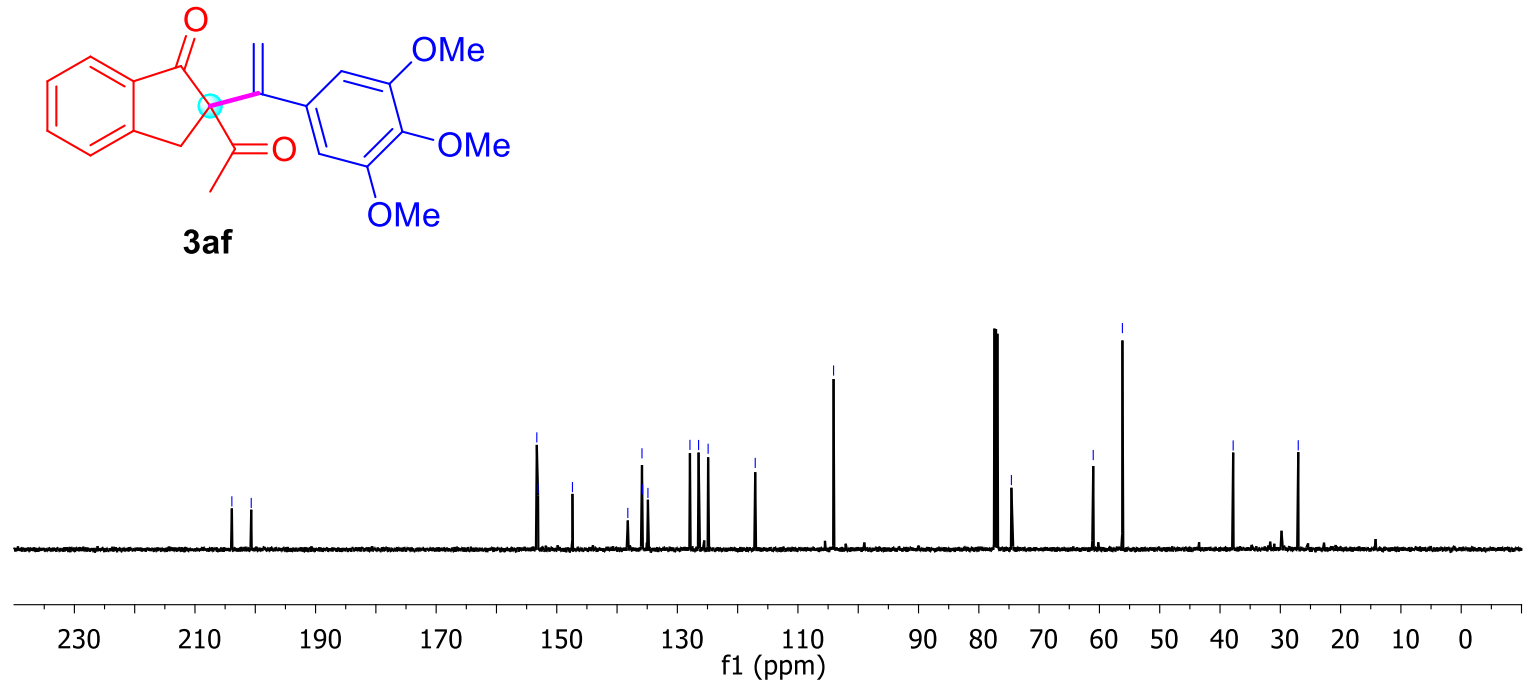
${ }^{1} \mathrm{H}$ NMR (400 MHz, CDCl3):

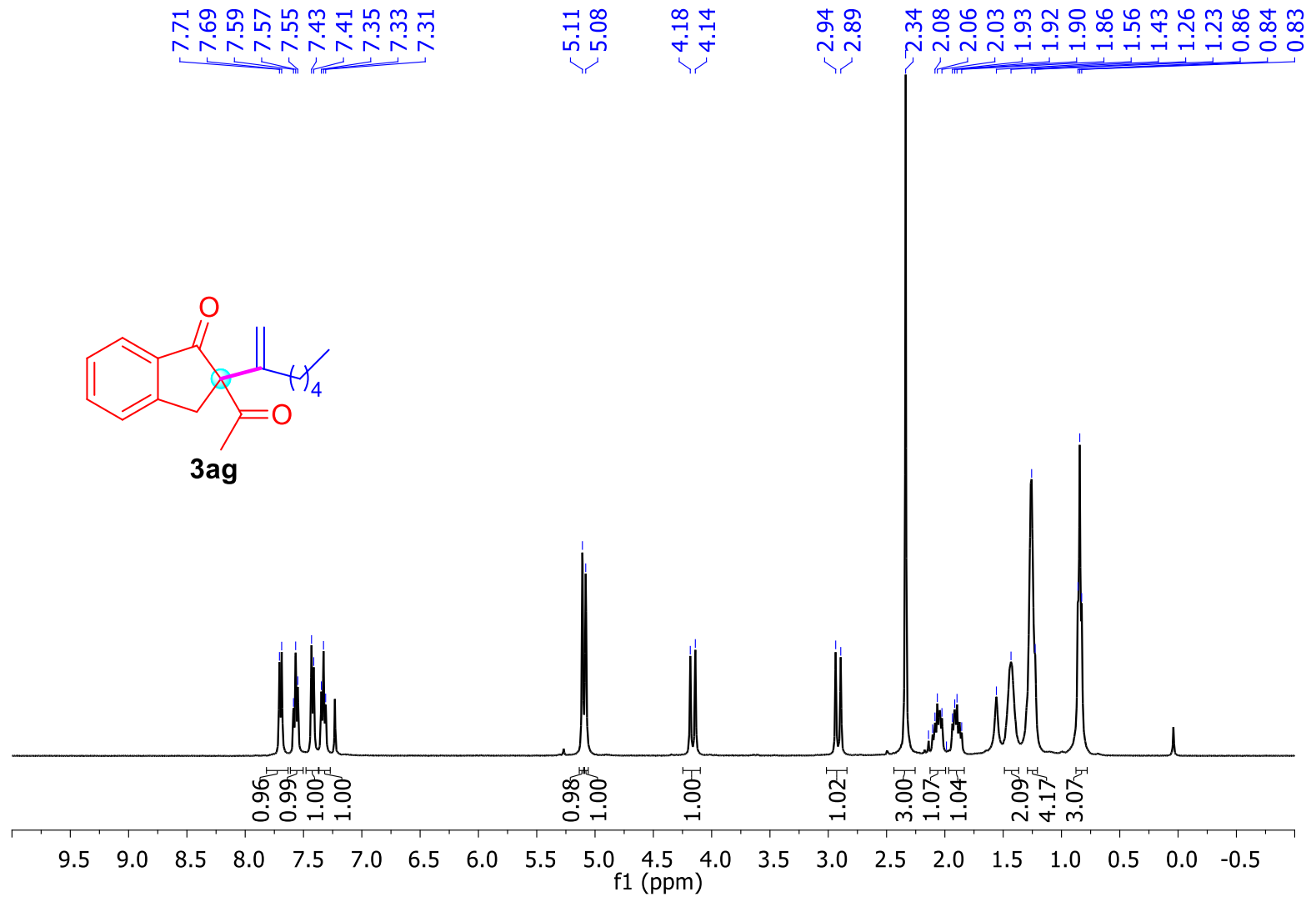

${ }^{13} \mathrm{C}$ NMR (126 MHz, CDCl3):

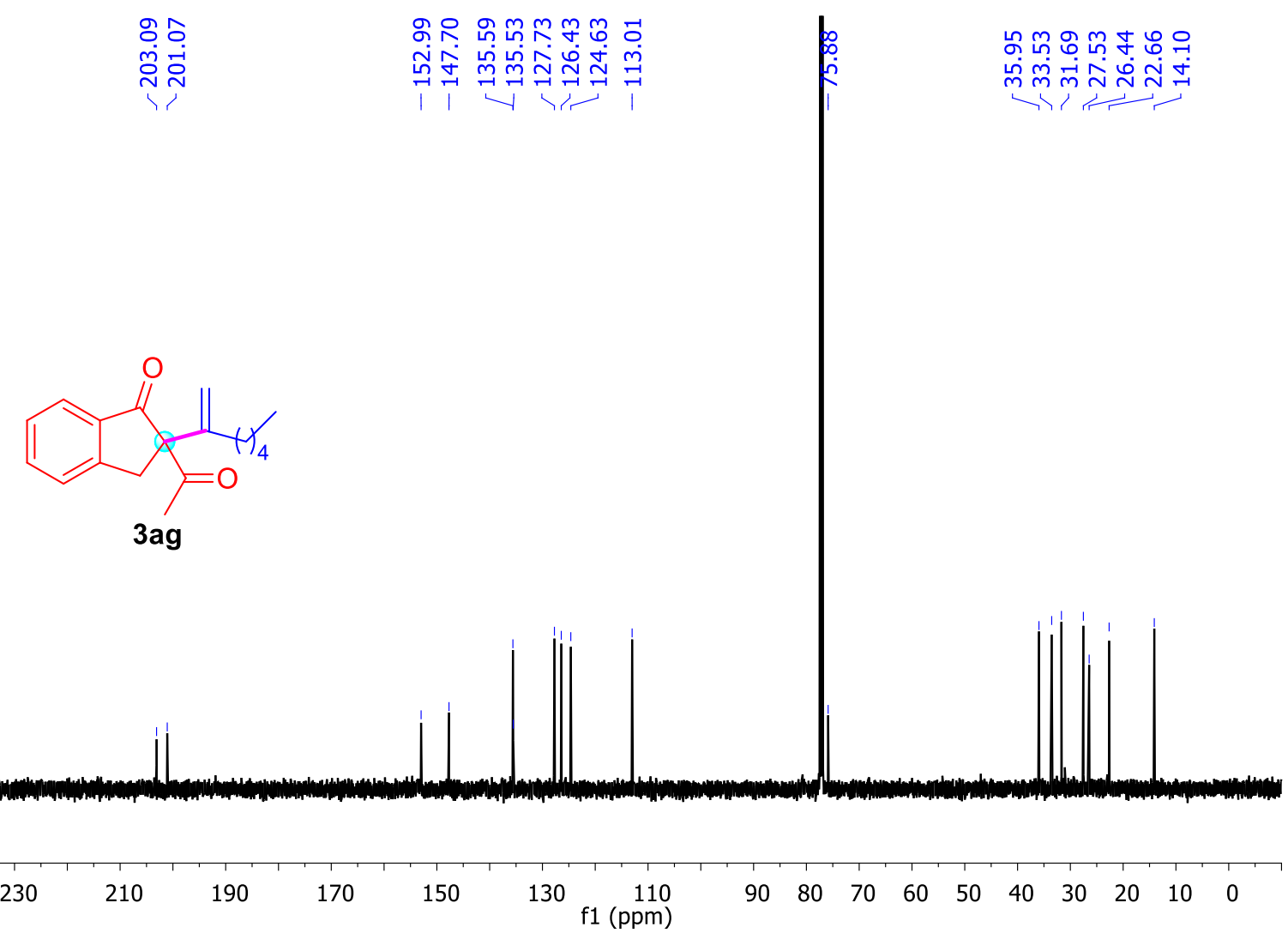


${ }^{1}$ H NMR (400 MHz, CDCl3):

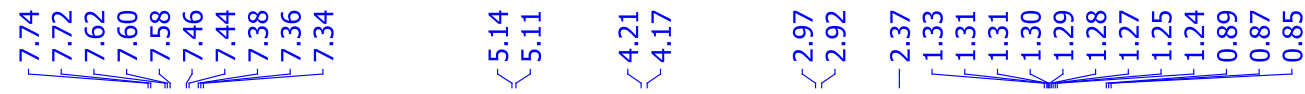

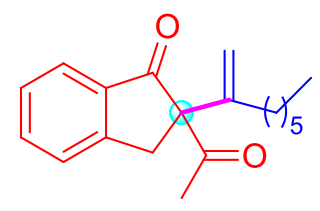

3ah

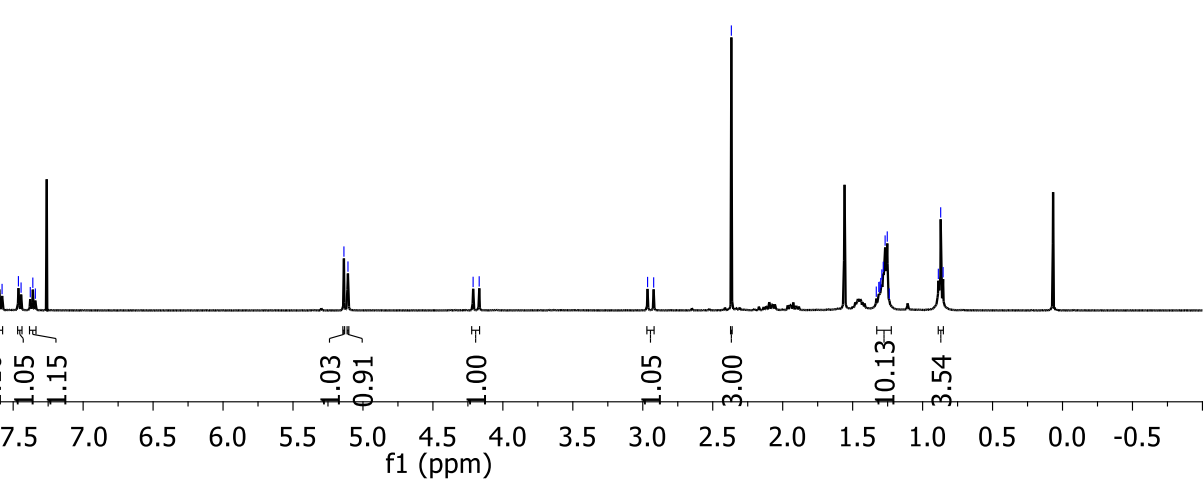

${ }^{13} \mathrm{C}$ NMR (126 MHz, CDCl3):

구요

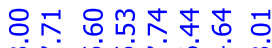

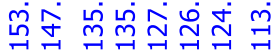

bo

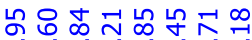

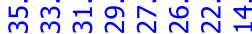

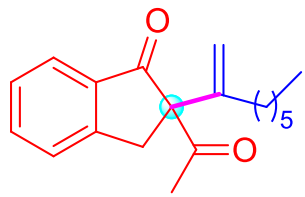

$3 a h$ 
${ }^{1}$ H NMR (400 MHz, $\left.\mathrm{CDCl}_{3}\right)$ :

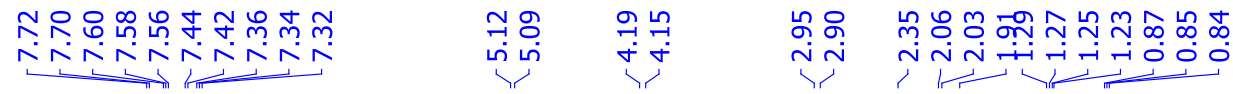

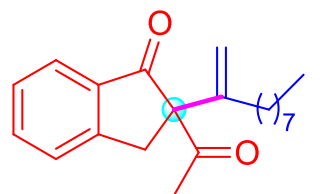

3ai

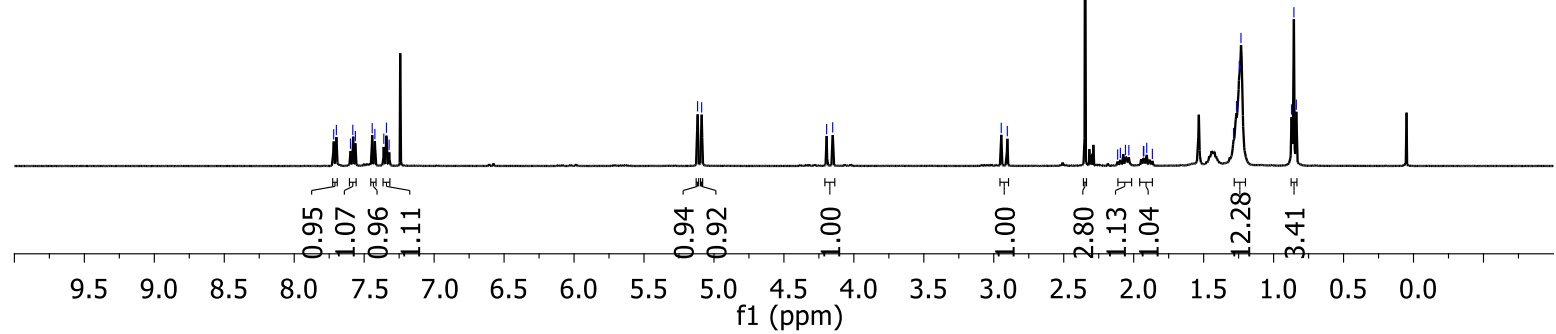

${ }^{13} \mathrm{C}$ NMR (126 MHz, CDCl3):

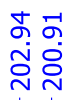

m

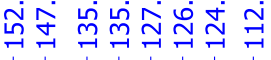

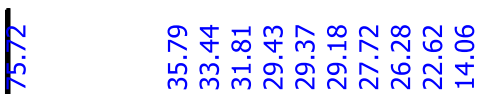

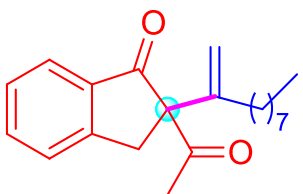

3ai

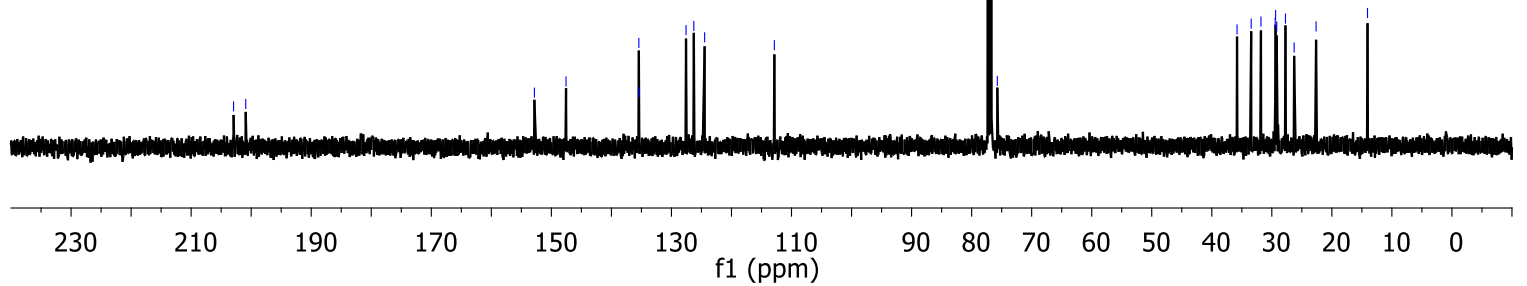


${ }^{1} \mathrm{H}$ NMR (400 MHz, CDCl $)$ :

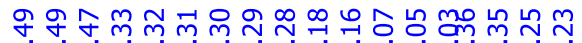

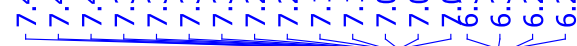

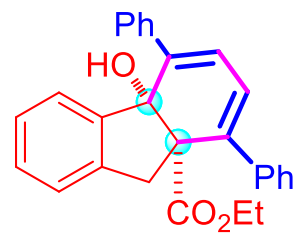

5 aa

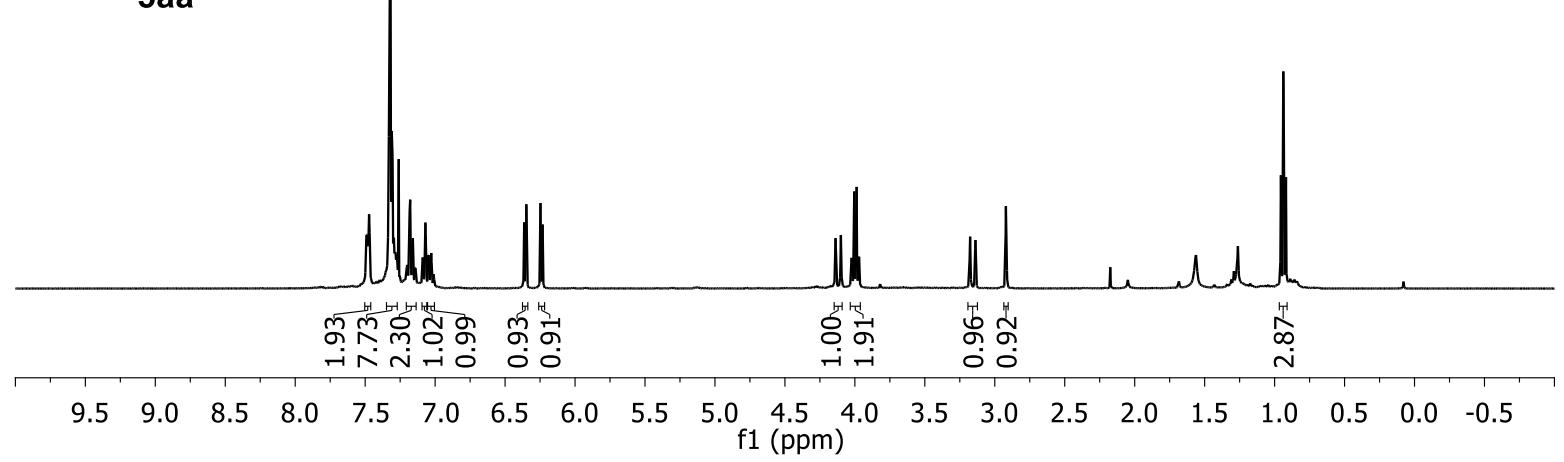

${ }^{13} \mathrm{C}$ NMR (101 MHz, CDCl3):

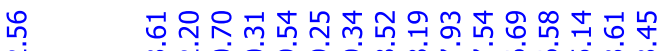

I

$m$
ñ
$\infty$
1

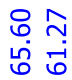

ำ

$m$
$\infty$
$\stackrel{m}{1}$<smiles>CCOC(=O)C1(O)C2C(c3ccccc3)=CC=C(c3ccccc3)C1(O)c1ccccc12</smiles>

5 aa

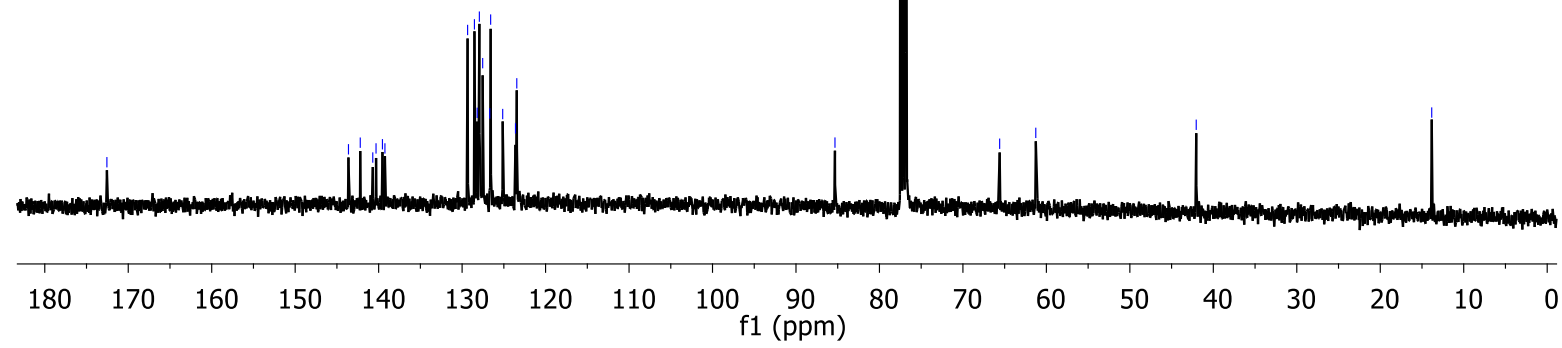


${ }^{1} \mathrm{H}$ NMR (400 MHz, CDCl3):

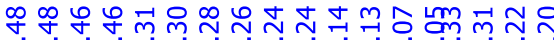

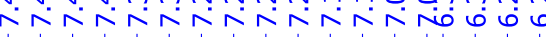

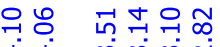

+ं

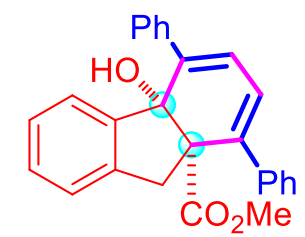

$5 \mathrm{ba}$

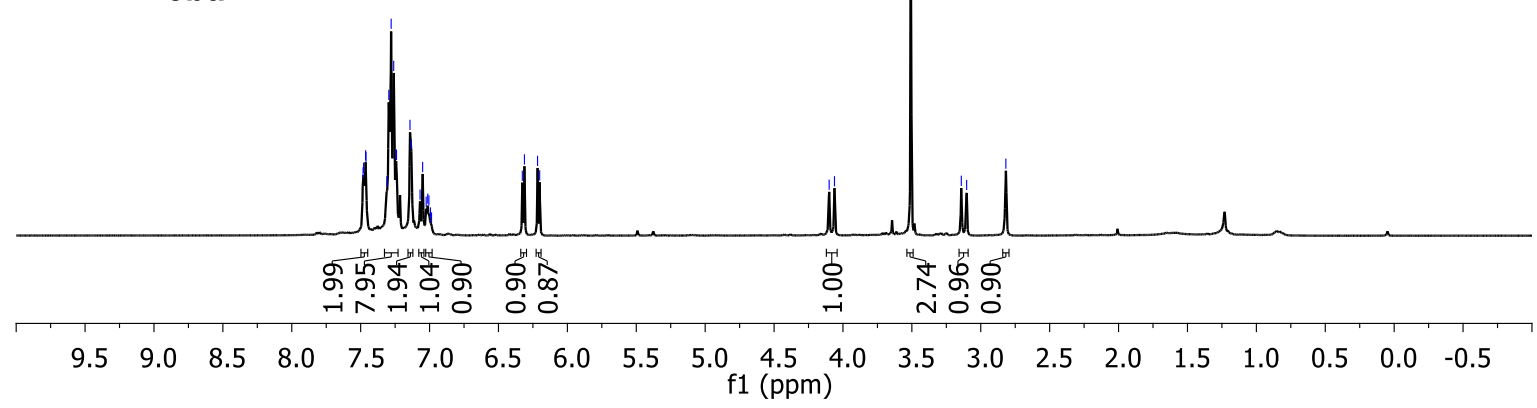

${ }^{13} \mathrm{C}$ NMR (101 MHz, $\left.\mathrm{CDCl}_{3}\right)$ :

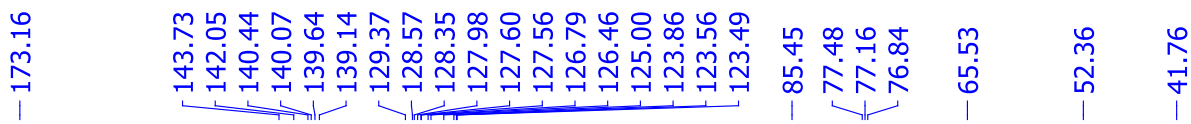

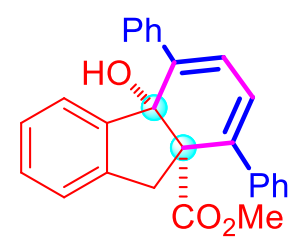

5 ba

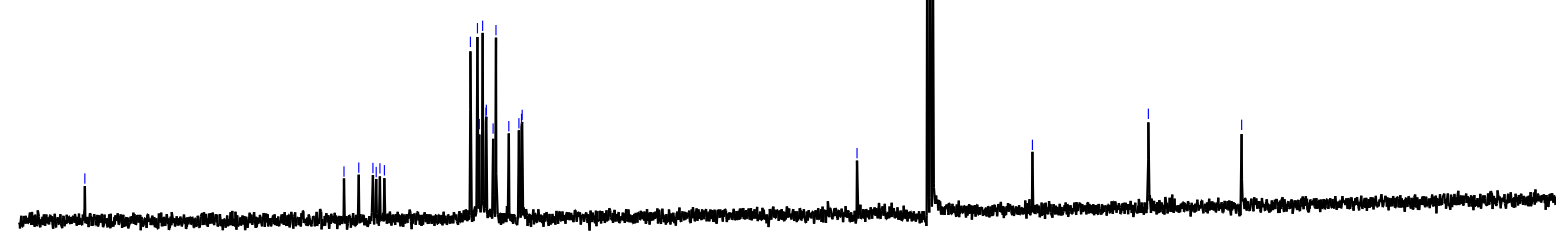

180

170

$160150 \quad 140$

130

120

110

$100 \underset{\mathrm{f} 1}{9} \mathrm{90}$

$80 \quad 70 \quad 60$

$50 \quad 40$

10 
${ }^{1} \mathrm{H}$ NMR (400 MHz, CDCl3):

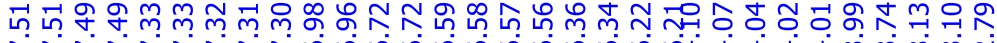

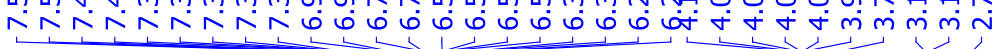

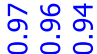

잉

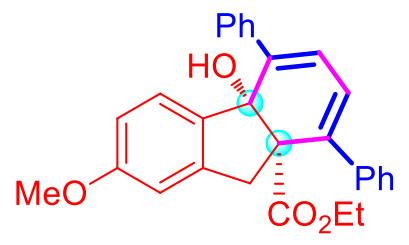

$5 \mathrm{ca}$

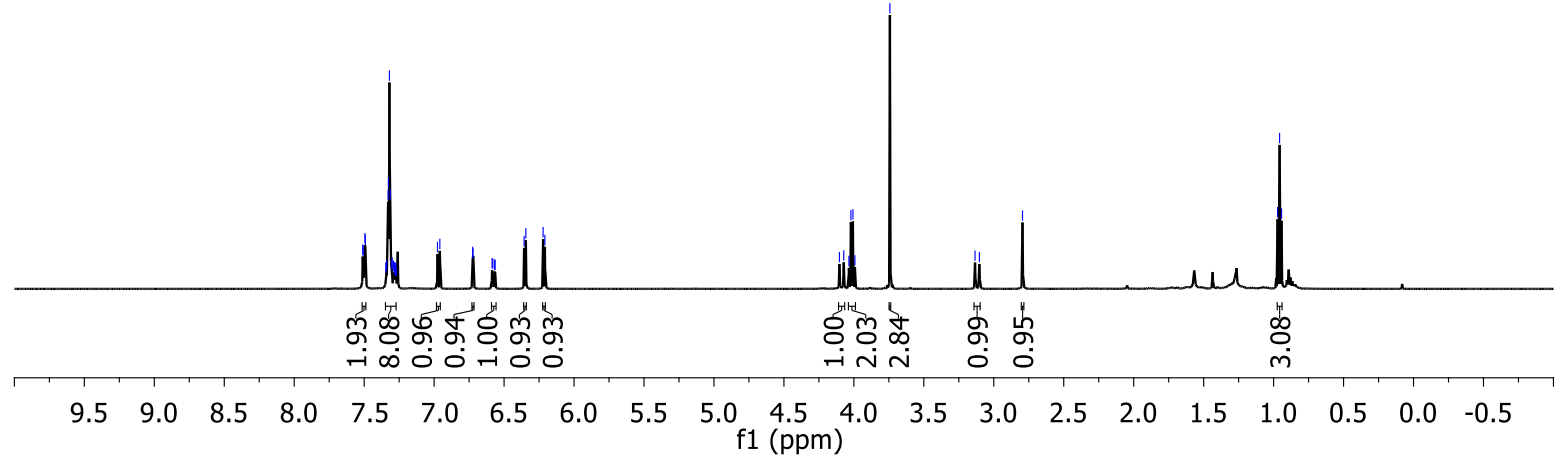

${ }^{13} \mathrm{C}$ NMR (126 MHz, CDCl3):

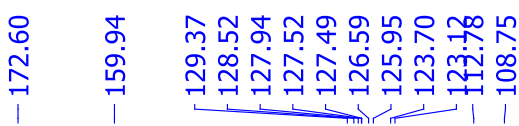

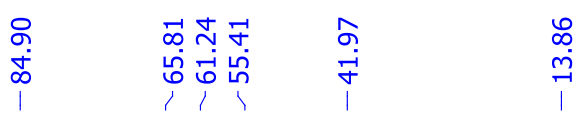

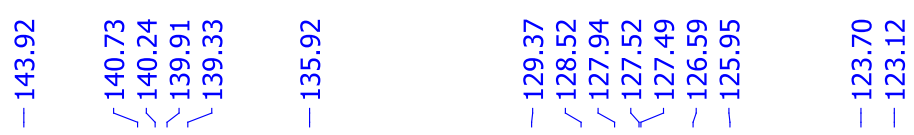<smiles>CCOC(=O)C1(O)C2c3ccccc3C1c1cc(OC)ccc12</smiles>
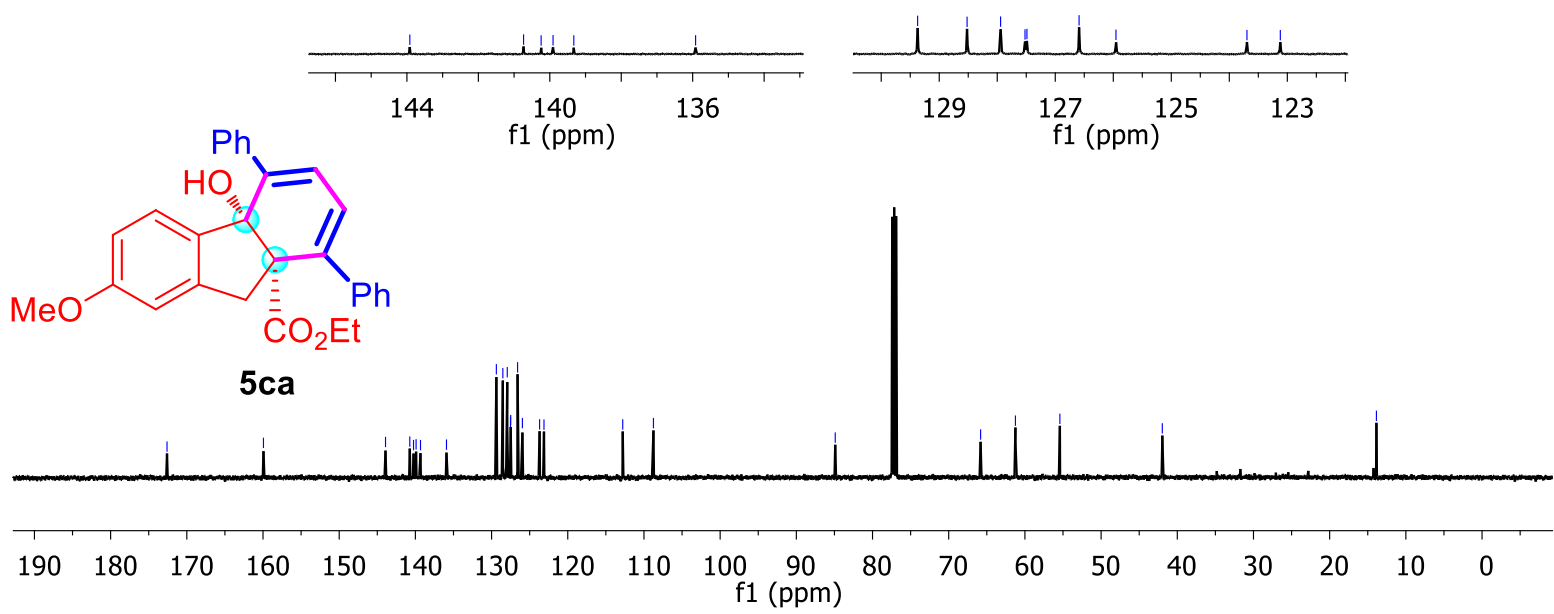
${ }^{1} \mathrm{H}$ NMR (400 MHz, $\left.\mathrm{CDCl}_{3}\right)$ :

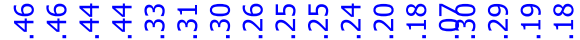

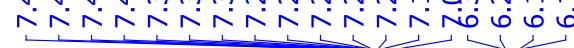

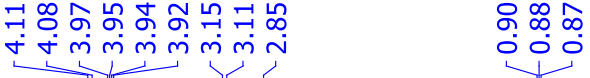<smiles>CCOC(=O)C1(O)C(c2ccccc2)=CC=C(c2ccccc2)C1(O)c1ccccc1</smiles>

5da

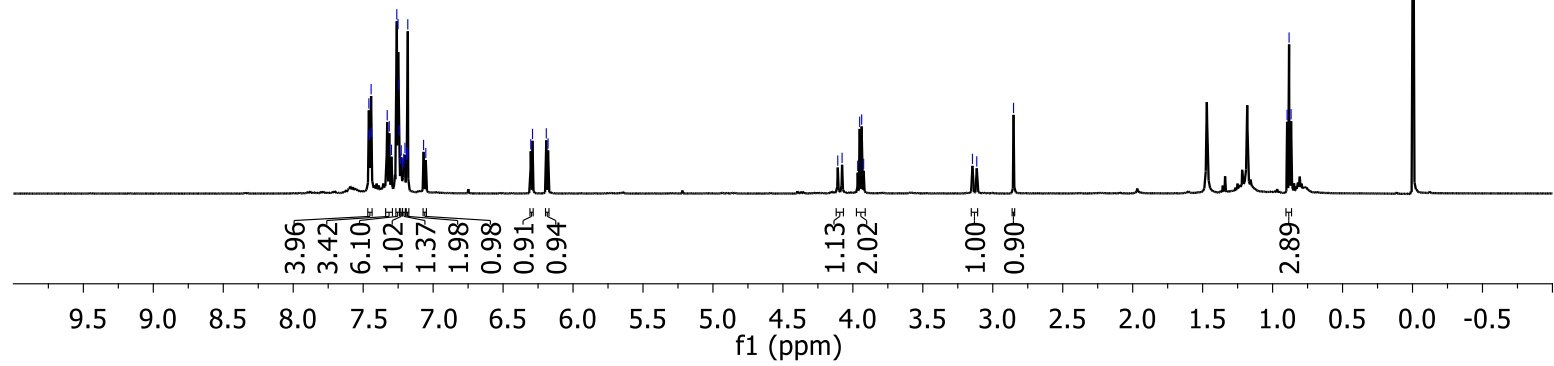

${ }^{13} \mathrm{C}$ NMR (126 MHz, CDCl3):

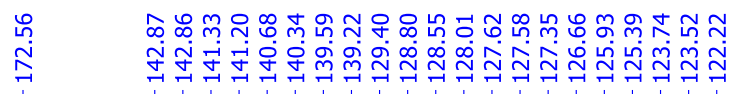

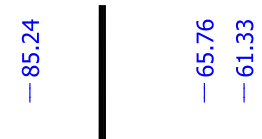

$\stackrel{\overrightarrow{0}}{\stackrel{4}{i}}$

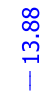<smiles>CCOC(=O)C1C2C(c3ccccc3)=CC=C(c3ccccc3)C1(O)Cc1cc(-c3ccccc3)ccc12</smiles>

$5 d a$

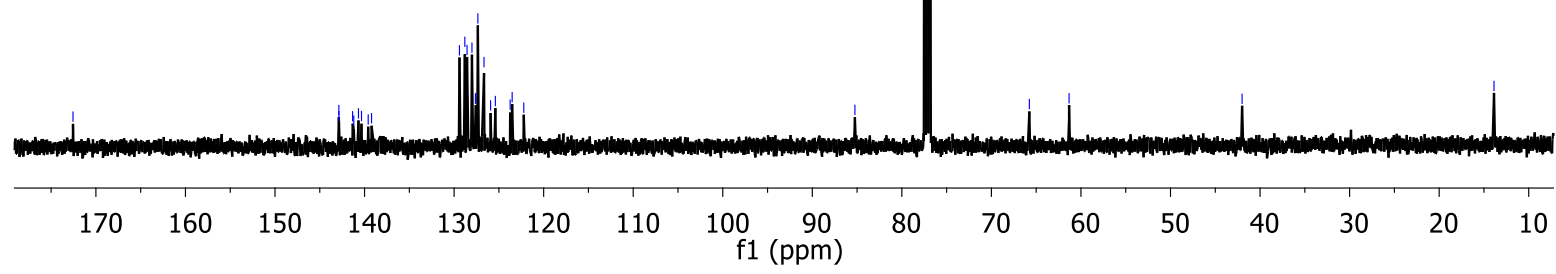


${ }^{1} \mathrm{H}$ NMR (400 MHz, $\left.\mathrm{CDCl}_{3}\right)$ :

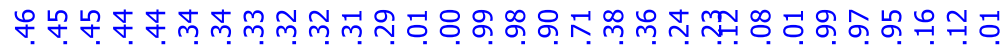

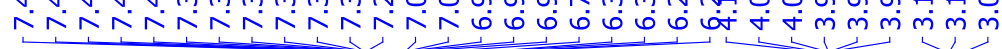<smiles>CCOC(=O)C1(c2ccccc2)Cc2cc(F)ccc2C1(O)c1ccccc1</smiles>

5ea

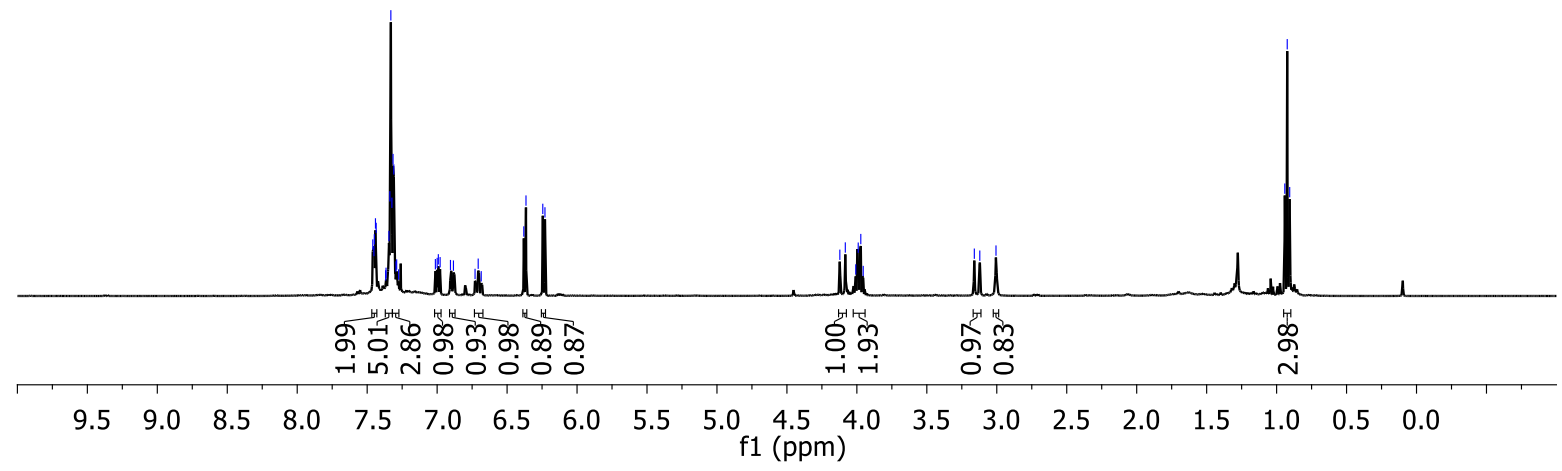

${ }^{13}$ C NMR (126 MHz, CDCl3):

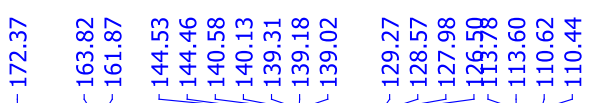

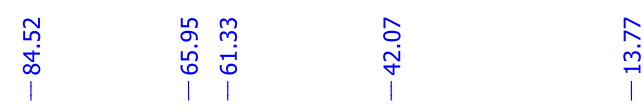

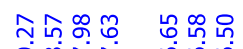

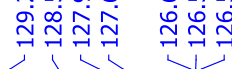

พִ mิ

$\stackrel{\overbrace{7}}{\underset{\sim}{\sim}}$

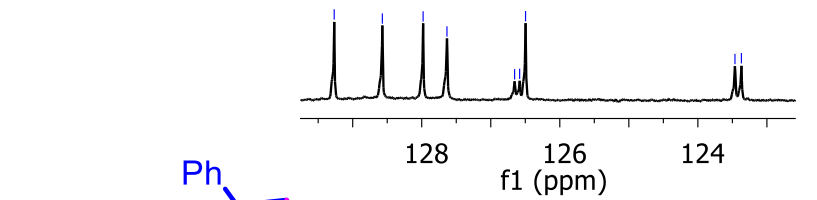<smiles>CCOC(=O)[C@@]12Cc3cc(F)ccc3[C@@]1(O)C(c1ccccc1)=CC=C2c1ccccc1</smiles>

1 (ppm)

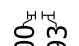

$1(\mathrm{ppm})$

\section{(1)}

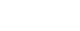


${ }^{19}$ F NMR (471 MHz, $\left.\mathrm{CDCl}_{3}\right)$ :

$$
\underset{\substack{f \\ \stackrel{5}{i}}}{i}
$$

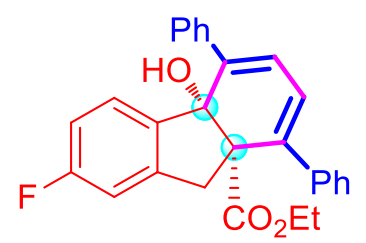

5ea

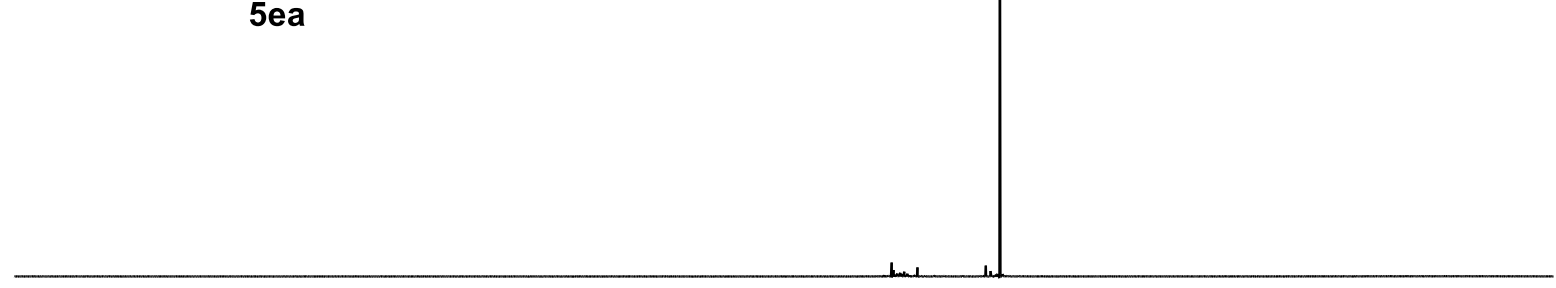

\begin{tabular}{lllllllllllllllll}
\hline 20 & 10 & 0 & -10 & -20 & -30 & -40 & -50 & -60 & -70 & -80 & -90 & -100 & -120 & -140 & -160 & -180 \\
\hline
\end{tabular}

\begin{tabular}{|c|c|c|}
\hline 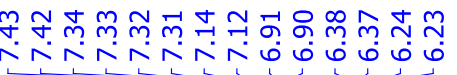 & 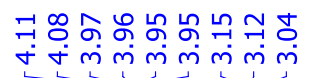 & नَ' ᄋ요 \\
\hline
\end{tabular}

${ }^{1}$ H NMR (400 MHz, CDCl3):<smiles>CCOC(=O)C1=CC=C(c2ccccc2)[C@]2(O)c3ccc(Br)cc3C[C@]12c1ccccc1</smiles>

$5 f a$

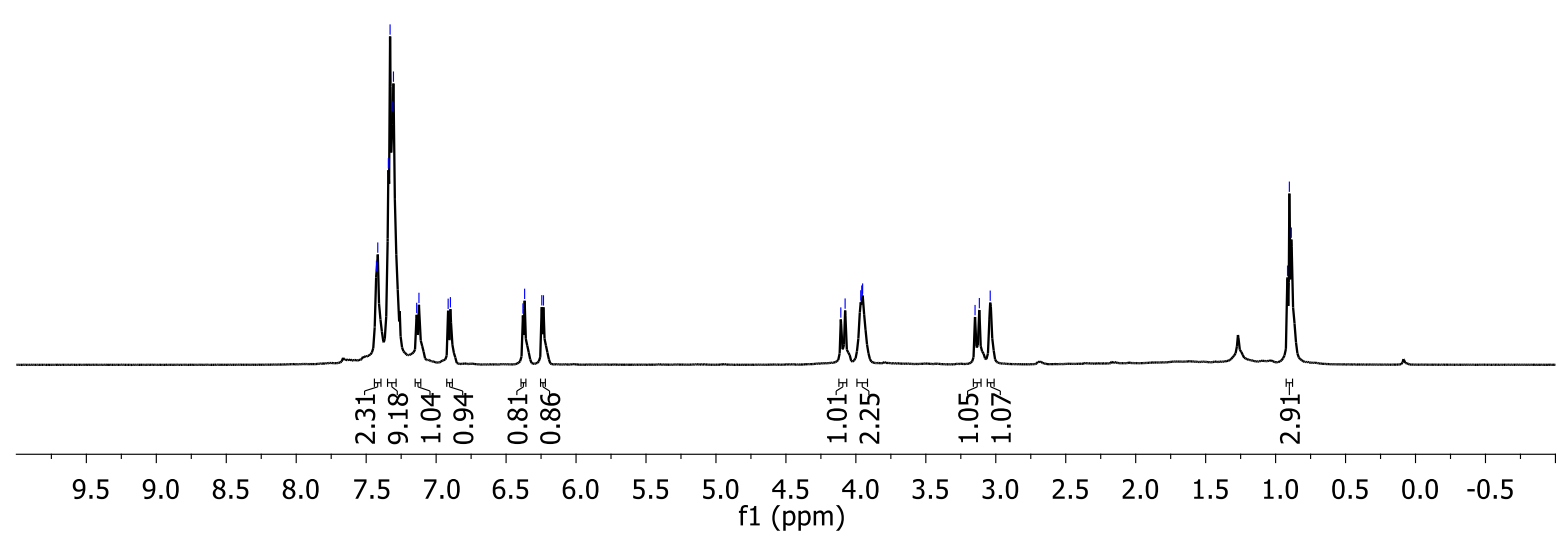


${ }^{13} \mathrm{C}$ NMR (126 MHz, $\left.\mathrm{CDCl}_{3}\right)$ :

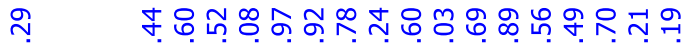

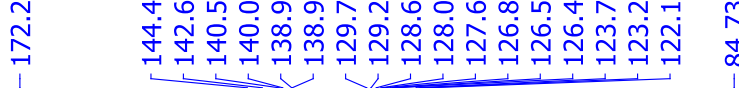

$\stackrel{\infty}{\stackrel{m}{m}}$

$\stackrel{m}{\stackrel{m}{\mathfrak{T}}}$

$\stackrel{0}{\stackrel{0}{\sim}}$<smiles>CCOC(=O)C1=CC=C(c2ccccc2)C2(O)c3ccc(Br)cc3CC12c1ccccc1</smiles>

$5 f a$

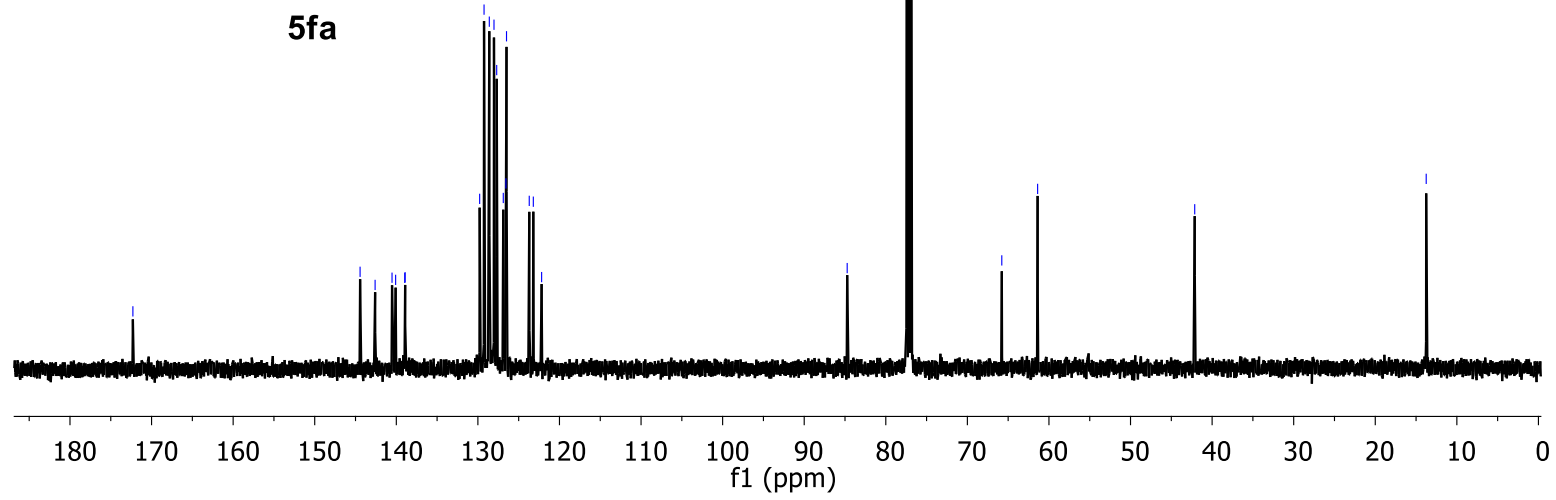

${ }^{1} \mathrm{H}$ NMR (400 MHz, $\left.\mathrm{CDCl}_{3}\right)$ :

우울ํำ

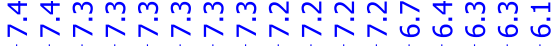

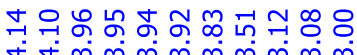

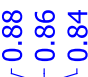<smiles>CCOC(=O)C1(c2ccccc2)C(c2ccccc2)=CC=C(c2ccccc2)C1(O)c1ccccc1</smiles>

5 ga

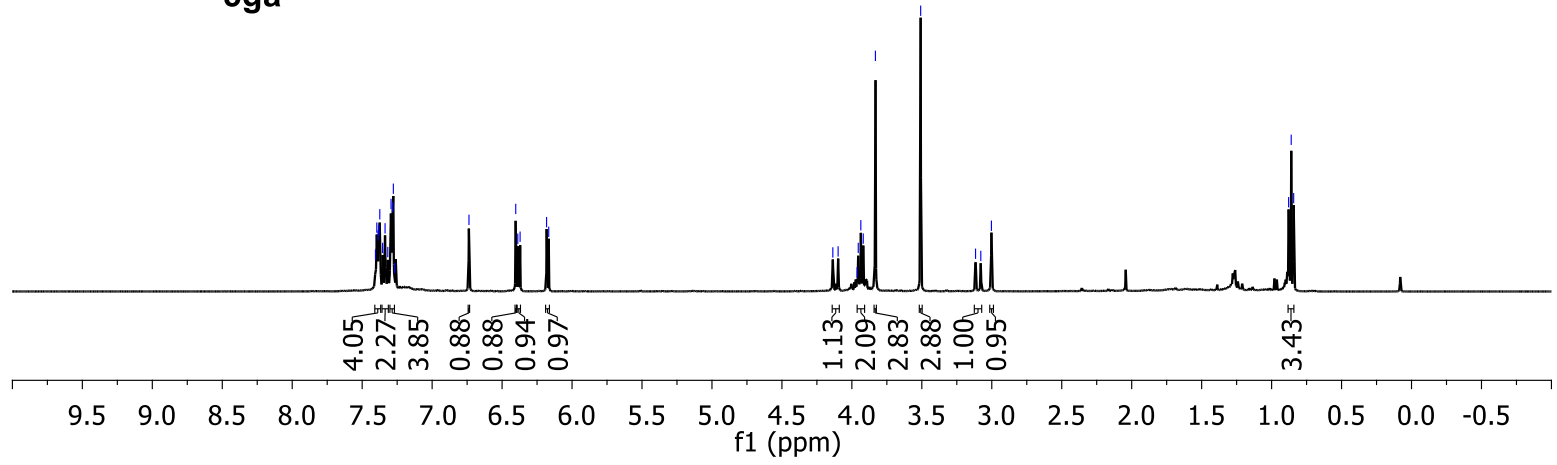


${ }^{13} \mathrm{C}$ NMR (126 MHz, CDCl3):

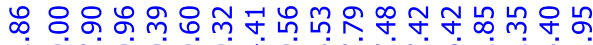

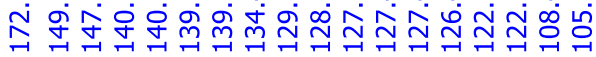

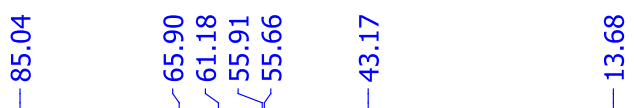

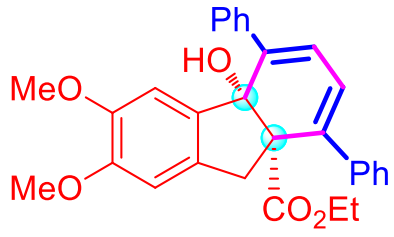

$5 g a$

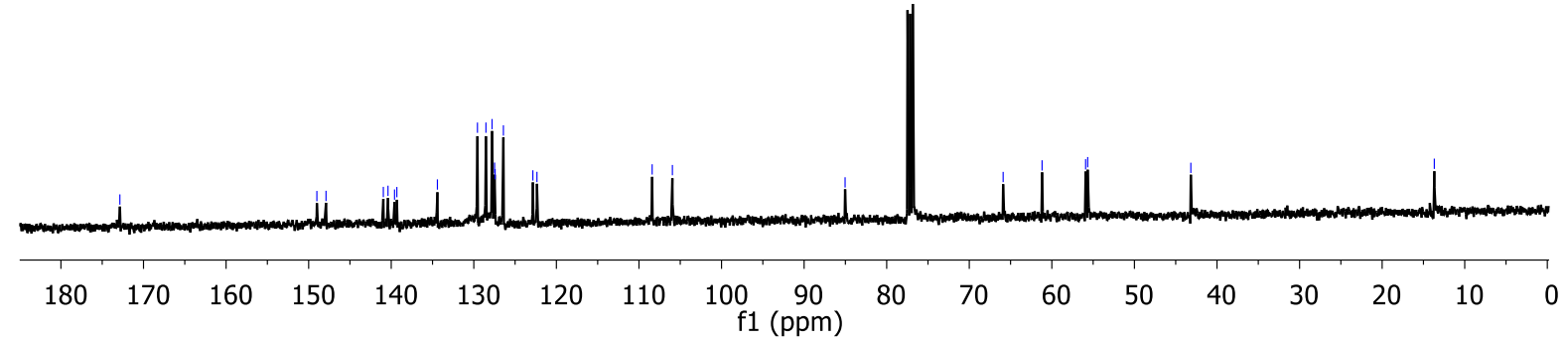

${ }^{1} \mathrm{H}$ NMR (400 MHz, CDCl3):

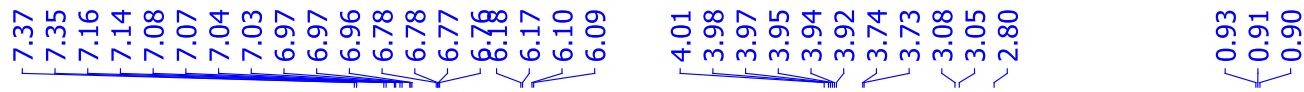

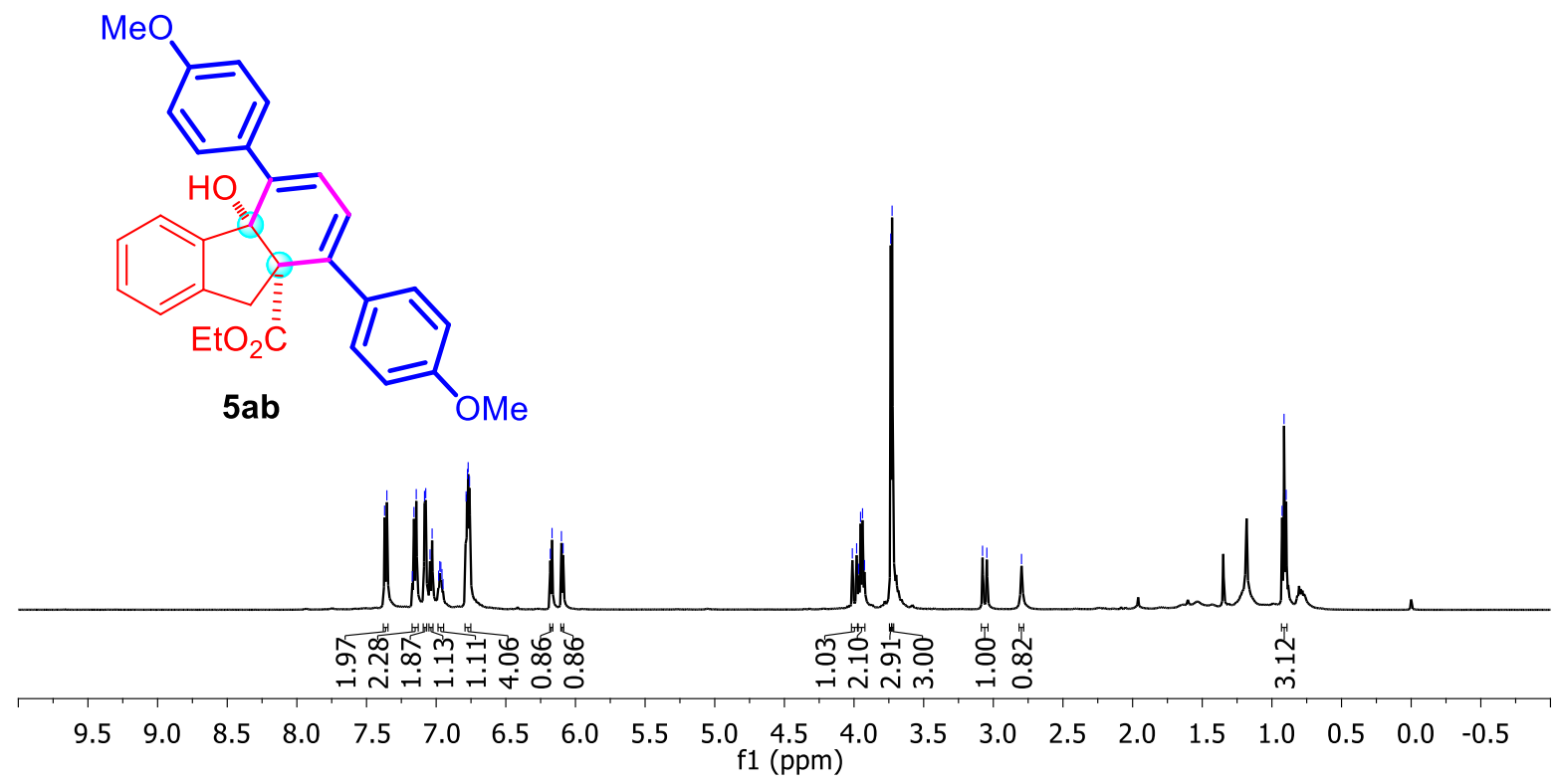


${ }^{13} \mathrm{C}$ NMR (126 MHz, $\left.\mathrm{CDCl}_{3}\right)$ :

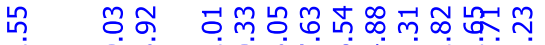

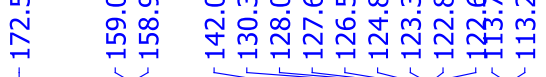

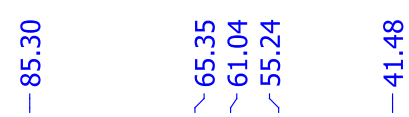

$\stackrel{\infty}{\infty}$

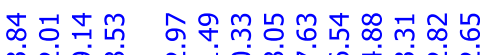

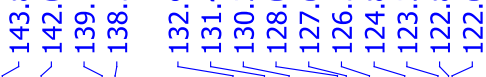

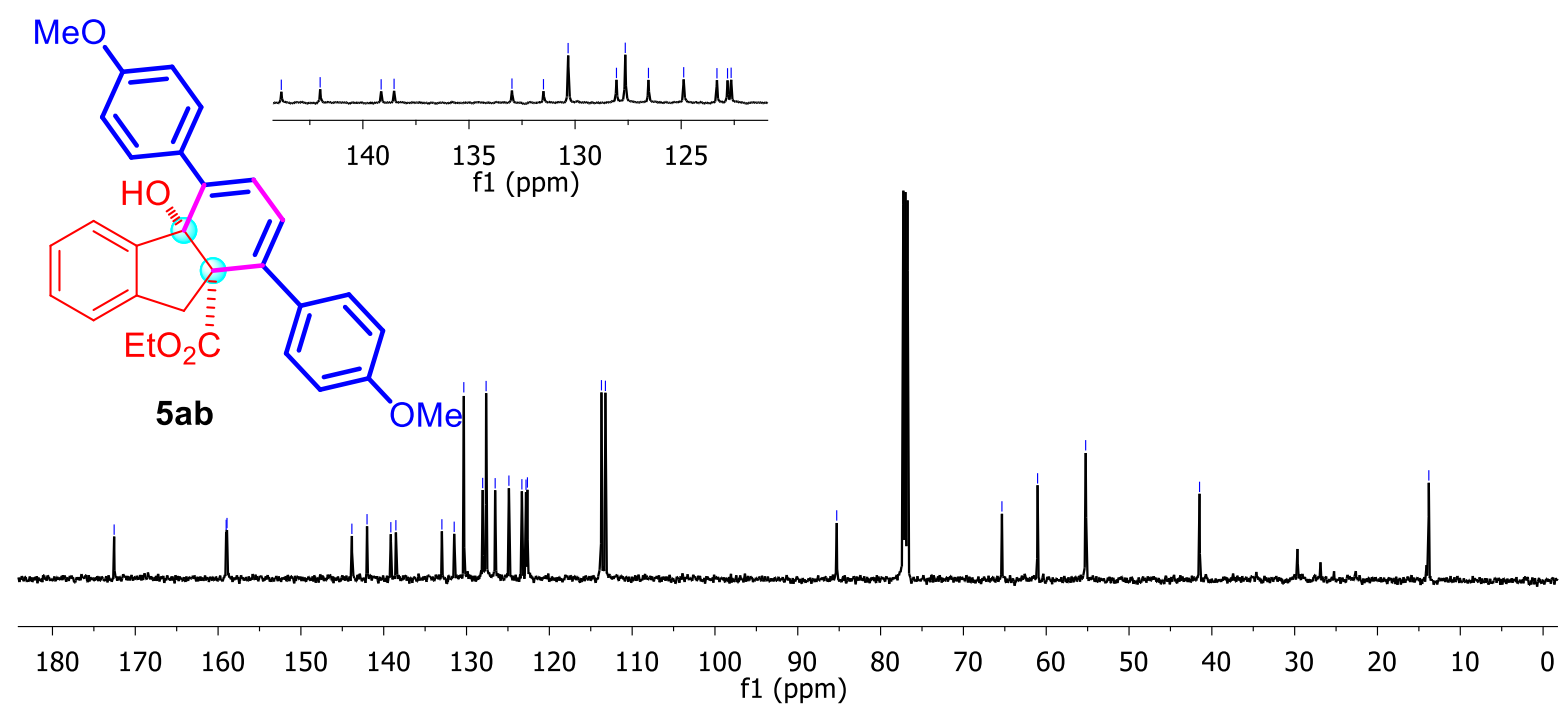

${ }^{1} \mathrm{H}$ NMR (400 MHz, CDCl3):

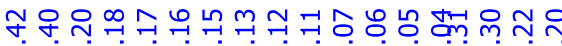

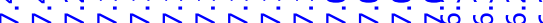

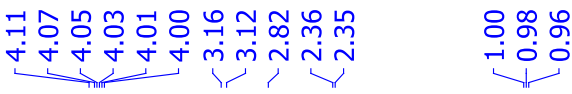

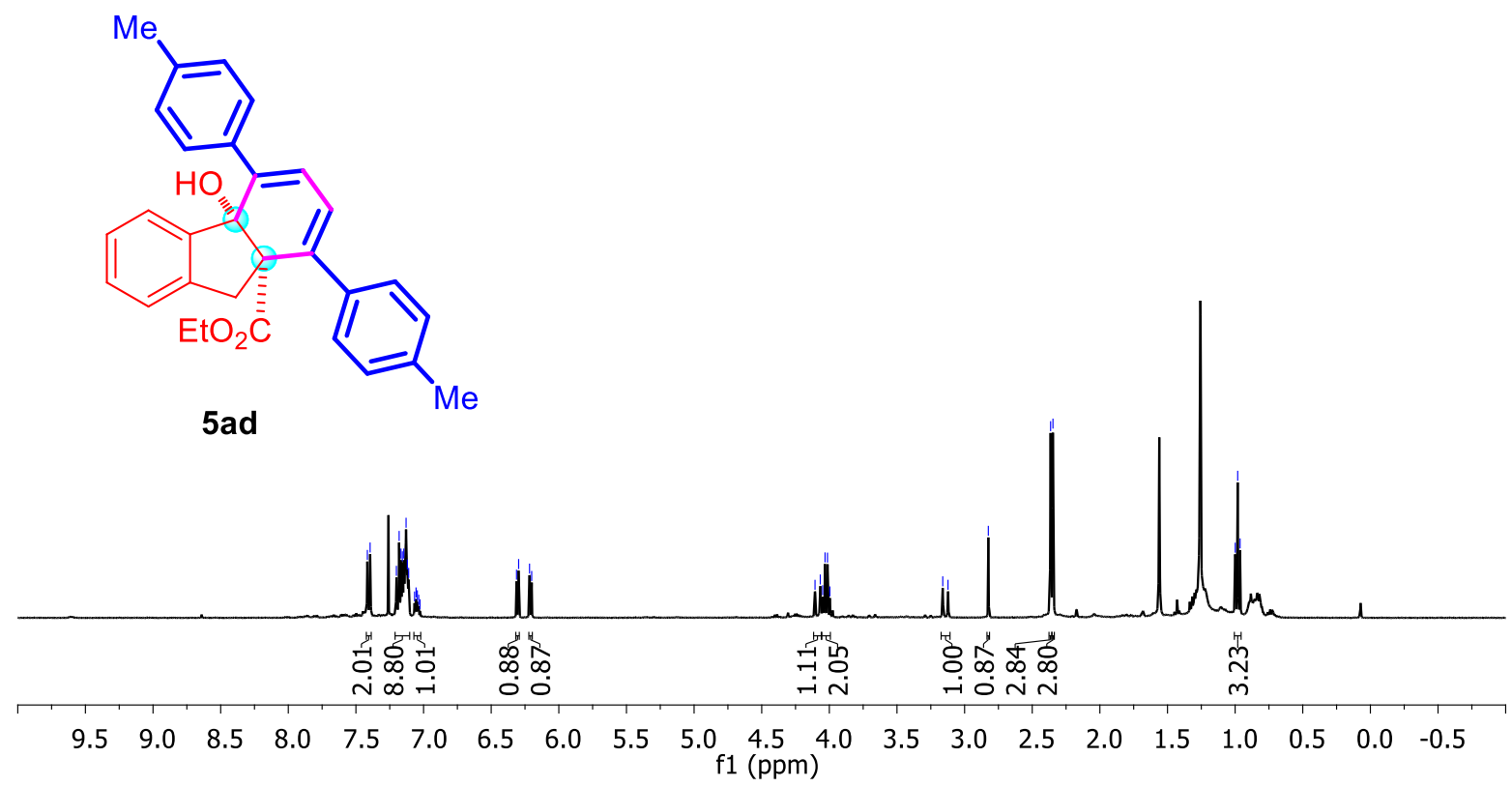


${ }^{13} \mathrm{C}$ NMR (126 $\left.\mathrm{MHz}, \mathrm{CDCl}_{3}\right)$ :

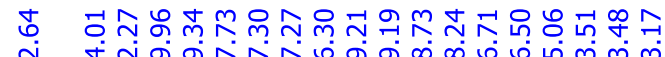

ㄱ.궉

$\overrightarrow{1}$
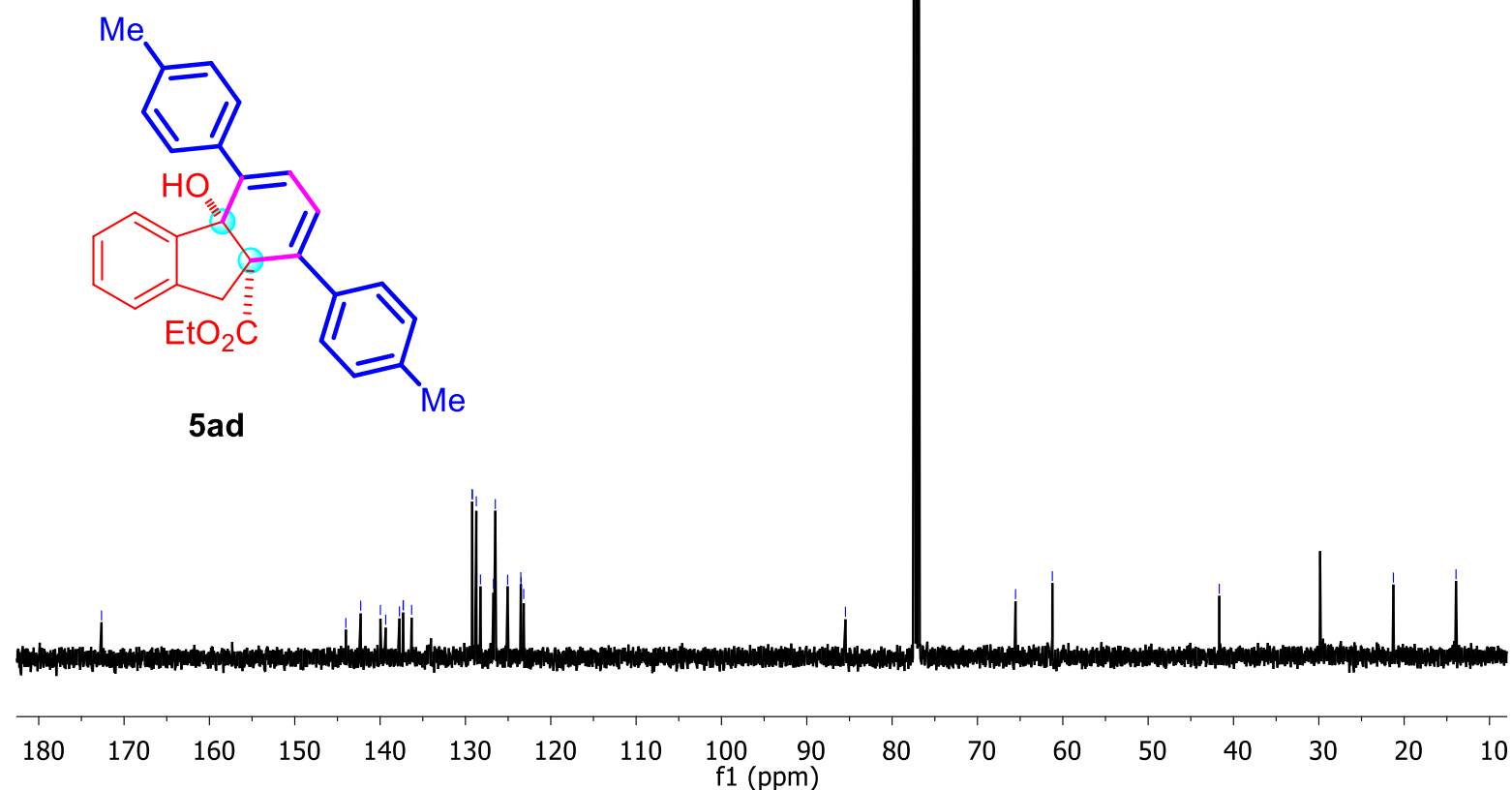

${ }^{1} \mathrm{H}$ NMR (400 MHz, $\left.\mathrm{CDCl}_{3}\right)$ :

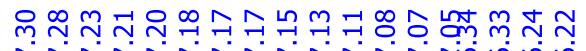

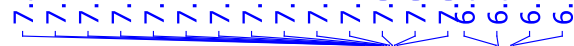

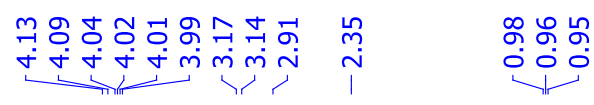<smiles>CCOC(=O)C1(O)c2ccccc2OC12C(c1cccc(C)c1)=CC=C2c1cccc(C)c1</smiles>

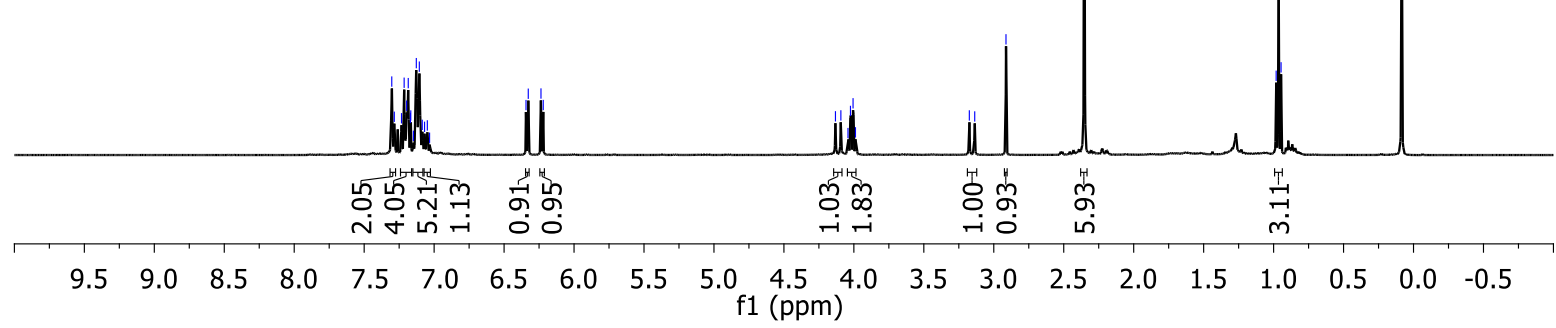


${ }^{13} \mathrm{C}$ NMR (101 MHz, $\left.\mathrm{CDCl}_{3}\right)$ :

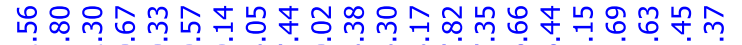

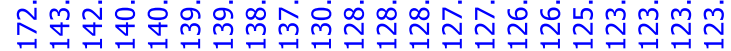

$\stackrel{\infty}{m}$
in
$\infty$

๓ุ․ 구

ถู่



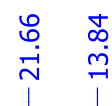

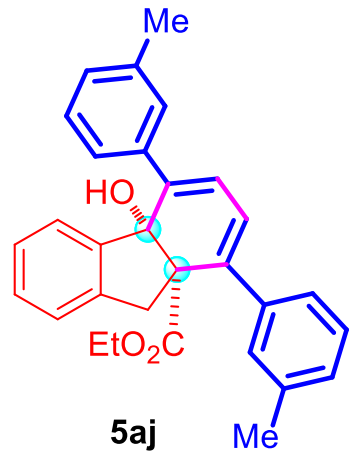

5aj

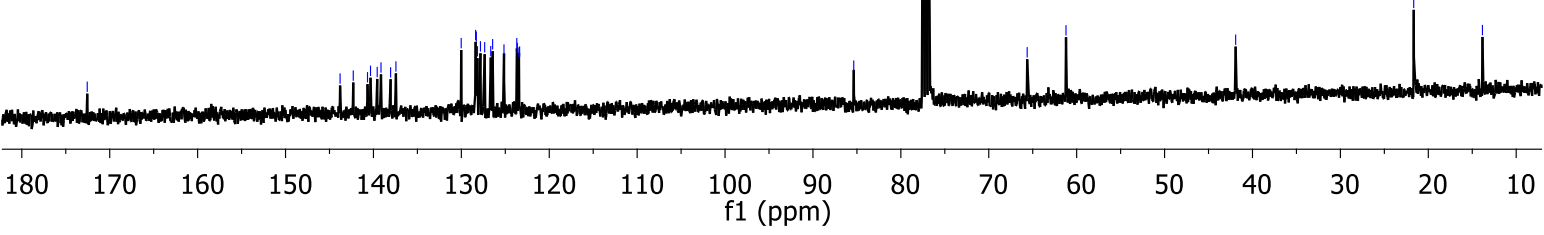

${ }^{1} \mathrm{H}$ NMR (400 MHz, CDCl 3$)$ :

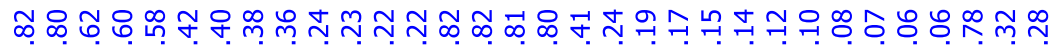

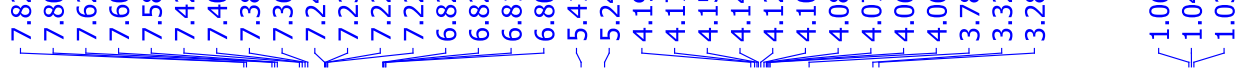

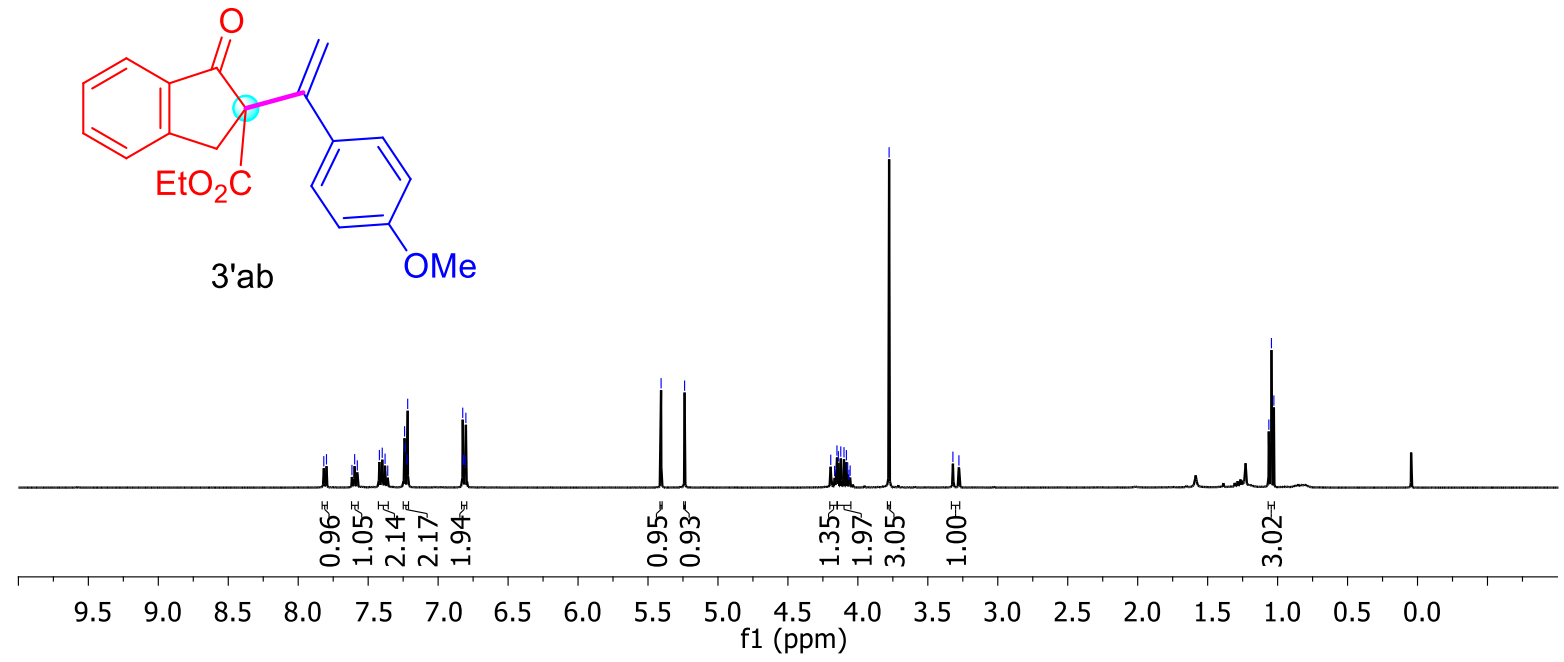


${ }^{13} \mathrm{C}$ NMR (126 $\left.\mathrm{MHz}, \mathrm{CDCl}_{3}\right)$ :

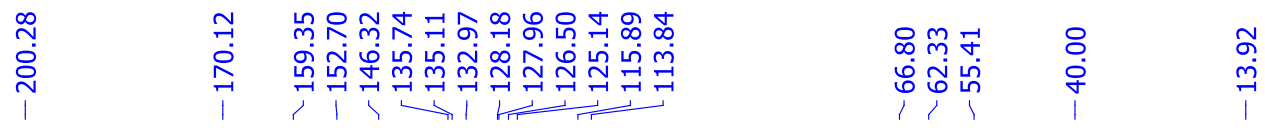

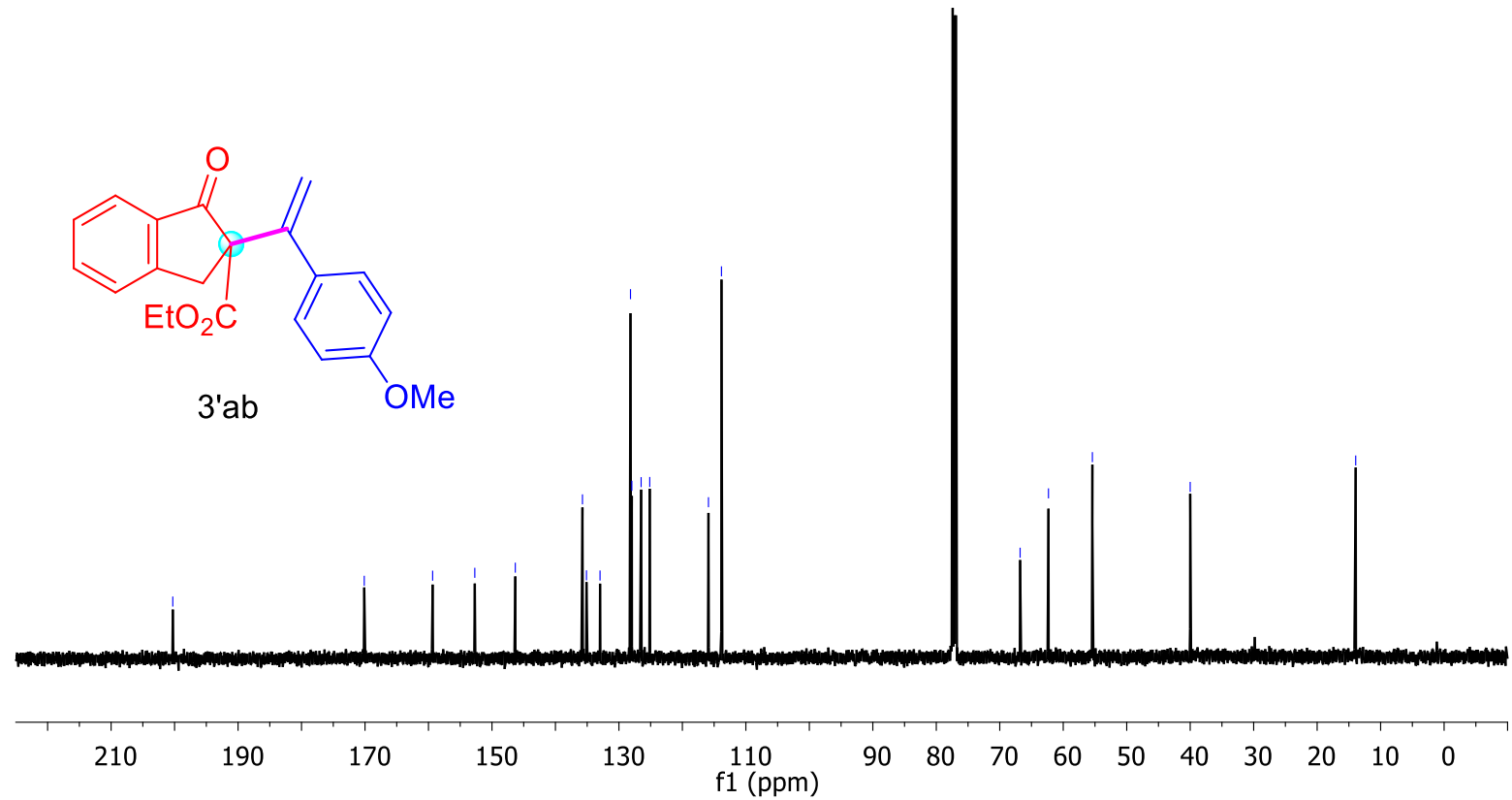

